\title{
A graphical technique for the design of water-using networks in batch processes
}

\author{
Cheng-Liang Chen*, Jui-Yuan Lee \\ Department of Chemical Engineering, National Taiwan University, Taipei 10617, Taiwan, ROC
}

\section{A R T I C L E I N F O}

\section{Article history:}

Received 16 January 2008

Received in revised form 21 April 2008

Accepted 24 April 2008

Available online 3 May 2008

\section{Keywords:}

Batch process

Graphical approach

Network design

Water integration

\begin{abstract}
A B S T R A C T
This paper presents a graphical technique for the design of water-using networks in batch plants. Water integration is achieved by exploiting all possibilities of water reuse/recycle to minimize not only freshwater consumption, but also wastewater generation. Since time limitation for unmatched operating periods may be the primary barrier to the integration in batch processes, the installation of storage facilities is quite common to enhance the water recovery. For that reason, the cost in terms of storage facilities becomes another issue to be considered. This work is focused on network design, like the second stage of conventional pinch analyses. Some useful concepts and principles addressed in literatures are adopted to help the design of batch water network and to ensure the maximum recovery, thus the utility usage, the network structure and the storage policy can be obtained through the analysis. Once the freshwater expenditure is determined, workable ways are sought to cut the number of storage tanks and they also reduce the network complexity. In the context of this paper, a hybrid system that includes different type of water-using operations with distinct operating modes is taken into account to display the versatility of proposed approach. Furthermore, considering the fact that sometimes water reuse/recycle between certain operations is not allowed to prevent operational problems, the action of network design should be more deliberate owing to additional restraints. Therefore, the potential for water integration may be diminished, which means a less amount of water recovery. Finally, an illustrative example is provided to amplify the application of proposed approach. Like most graphical techniques, the presented work is restricted to a single key contaminant.
\end{abstract}

(c) 2008 Elsevier Ltd. All rights reserved.

\section{Introduction}

The rising costs of freshwater and effluent treatment, as well as the more stringent environmental legislation, currently drive the development of systematic methods for water integration in industry. Both freshwater consumption and wastewater generation can be minimized by maximizing the opportunities of in-plant water reuse. Wang and Smith (1994) presented a two-stage pinch technique for the analysis of water minimization problems. The concept of limiting composite curve was introduced to identify the pinch point (or the bottleneck) and target the minimum freshwater flowrate for the entire water system prior to the detailed network design. In their later work (Wang and Smith, 1995a), flowrate constraints were taken into consideration during the network synthesis. The major drawback of these works is that all water-using operations are formulated as a mass transfer process, and therefore the approach is not suitable for some operations not involving mass transfer, such as boiler, cooling tower and reactor system, etc.

\footnotetext{
* Corresponding author. Tel.: +886223636194; fax: +886223623040

E-mail address: CCL@ntu.edu.tw (C.-L. Chen).
}

For solving the more general problems, like a single process unit which has multiple aqueous inlet and/or outlet streams, Dhole et al. (1996) presented an alternative method. In their method, the aqueous input and output of all relevant water-using operations are regarded as water demands and water sources. The flowrate target is located by the water source and demand composite curves. However, Hallale (2002) pointed out that the targets provided by Dhole et al. (1996) are not the true targets as they depend on the mixing pattern. Besides, Hallale (2002) presented a new targeting technique with the water surplus diagram, which handled the mixing possibilities and resulted in the true pinch point and utility target. El-Halwagi et al. (2003) as well as Prakash and Shenoy (2005), respectively, developed a simpler non-iterative graphical approach with a set of newly introduced composite curves on a load-flowrate diagram, and furthermore Manan et al. (2004) also introduced a numerical technique of water cascade analysis to eliminate the tedious iterative step of the water surplus diagram. Recently, Liu et al. (2007a) presented a strategy for water minimization problems, to convert the non-mass transfer based operations into mass transfer based operations by the insertion of fictitious operations.

Apart from the targeting stage, several algorithmic procedures have been developed for the detailed design of water-using 
network. This includes the use of water grid diagram (Wang and Smith, 1994), water main method (Kuo and Smith, 1998; Feng and Seider, 2001), water source diagram (Castro et al., 1999; Gomes et al., 2007) for the fixed load problems; as well as source-sink mapping diagram (El-Halwagi, 1997), nearest neighbors algorithm (Prakash and Shenoy, 2005), heuristic-based approach (Liu et al., 2007a) for the fixed flowrate problems. Once the minimum flowrate targets are identified, any of the above design tools can be used to accomplish the corresponding network.

In contrast to the remarkable advances of network synthesis in continuous processes, there are only a few investigations on batch processes. Since batch processes have become the ordinary works in the production of specialty chemicals of high commercial values, the study of systematic approaches for water integration in batch plants appeals to academics and practitioners.

Wang and Smith (1995b) presented the first work of water minimization in batch processes. A graphical method is introduced where time is treated as the primary constraint ahead of concentration driving force. This method is applicable to the semi-continuous operations, as water reuse is permissible between operations with overlapping durations. Majozi et al. (2006) also presented a similar technique to consider the complete batch, as no intake and discharge during the operation. The drawback of these works is that they are limited to handle the mass transfer based operation. Foo et al. (2005) proposed the application of water cascade analysis which has the ability to deal with the non-mass transfer based operation. The significance of locating the correct targets has been stressed, and the authors also showed that the targeting technique for continuous processes can be validly extended to batch processes. However, the primary assumption of this work is that water sources with different concentrations are not allowed to mix, which may lead to an excessive number of storage tanks. Further studies for synthesizing the water reuse/recycle networks can also be found in literatures: Liu et al. (2007b) extended their former work and developed a time-dependent concentration interval analysis (CIA) method to solve the batch water-using system involving both mass and non-mass transfer based operations. Chan et al. (2008) presented a case study of water minimization in a polyvinyl chloride resins manufacturing plant, where an integrated approach was used for the mixed batch and continuous polymerization process.

Since different types of operations (fixed load and fixed flowrate) and operating modes (completely batch and semi-continuous) can coexist in practice, an effective design tool is needed to deal with such a hybrid batch water system comprising various operations. This article aims to present a versatile approach for the design of batch water-using networks with the newly introduced graphical representation. The proposed methodology is focused on network design, including the stream allocation and storage policy determination. For the presentation of analysis, a hypothetical example is provided. As shown in the later sections, the minimum freshwater consumption and the maximum water recovery can be ensured by the practice of some principles such as the necessary condition of optimality (Savelski and Bagajewicz, 2000) and the nearest neighbors algorithm (Prakash and Shenoy, 2005), even though the targeting step has been skipped.

\section{Problem statement}

A batch water system includes various types of water-using operations. Each of them consumes or generates a certain quality and quantity of water according to the job functions, where a single key contaminant is in concern. Moreover, the starting and finishing times of individual operations are predefined by a known schedule. Considering the mismatch of operating periods in batch processes, a set of storage tanks are placed into the system to improve the possibility

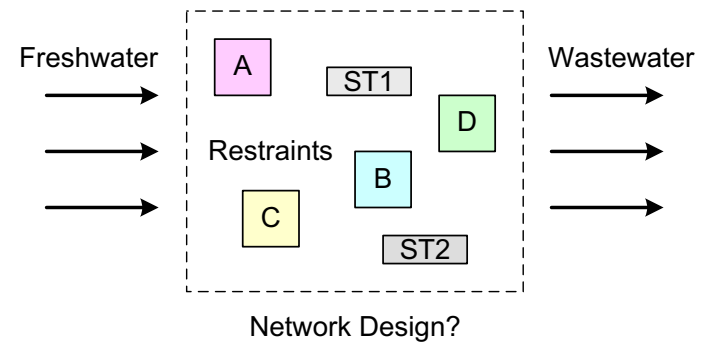

Fig. 1. Design problem of a batch water system.

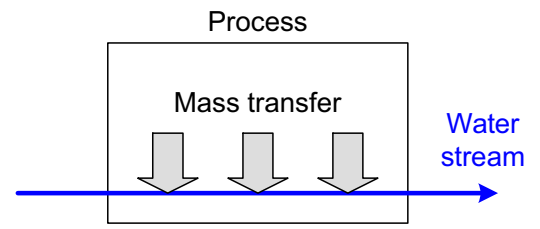

Fig. 2. General description of fixed load operations.

a

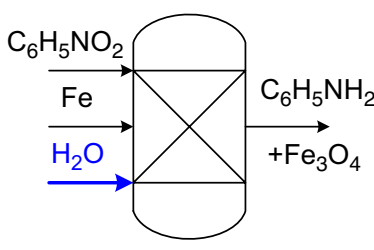

b
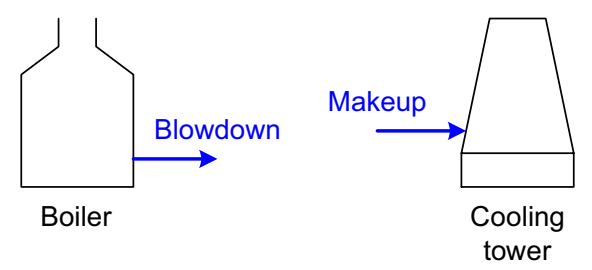

Fig. 3. Examples of fixed flowrate operations (Manan et al., 2004): (a) water fed as a reactant or withdrawn as a by-product; (b) water utilized as heating or cooling media.

of water integration. Fig. 1 illustrates the design problem, in which A, B, C and D represent the water-using operations, whereas ST1 and ST2 stand for the storage tanks. Freshwater is available as an external utility and wastewater will be discharged to the environment. The objective of network design is to determine the effective strategies which minimize the freshwater consumption, as well as the wastewater generation by maximizing the amount of water recovery among water-using operations. Sometimes practical restraints in design, e.g. no water recycling, will be imposed due to particular justifications.

\section{Classification of water-using operations}

Essentially, water-using operations can be classified to two broad categories (Hallale, 2002; Manan et al., 2004; Prakash and Shenoy, 2005) as discussed below.

The first category is mass transfer based, or fixed load operations, where water is utilized as a mass separating agent (MSA). As shown in Fig. 2, this type of operations is generally characterized by the mass transfer of contaminants from the process to the water stream passing through the unit. Typical examples include washing, extraction and scrubbing, etc. It is worthy to note that the inlet and outlet flowrates of a mass transfer process are usually assumed to 
be the same. Furthermore, the amount of transferable contaminant to be picked up, as well as the maximum allowable inlet and outlet concentrations for each operation are specified.

The second category is non-mass transfer based, or fixed flowrate operations. Except for an MSA, as shown in Fig. 3(a), water could be fed as a raw material or withdrawn as a product/byproduct in chemical reactions. Besides, Fig. 3(b) shows other cases of water being utilized as a heating or cooling medium. All inlet and outlet streams in such operations have specified flowrates which are not necessarily to be the same as each other, and sometimes there are only inlet or outlet streams. Furthermore, the outlet streams often leave at specific concentrations, and the inlet streams must be constrained by the maximum allowable concentrations. It is evident that the fixed flowrate operations are quite multiplex without a general description.

\section{Stream allocation and representation}

It is convenient to depict a water-using operation by its aqueous inlet and outlet streams which are the main interests in water integration. Moreover, these inlet and outlet streams can be considered separately as water demands and water sources. In other words, water is demanded to fulfill operations while the used water is discharged or forms a reusable source. The proposed graphical analysis in this work is carried out by selecting suitable water sources to satisfy each water demand along the time proceeding. For this purpose, we have generalized some major principles about how to assign the concentration and to establish the flowrate or the quantity of flow for each aqueous stream as the focus of this section. A new graphical representation, the quantity-time diagram is also introduced to support the analysis in batch processes. As the connections between sources and demands are visualized during the allocation procedure, the utility consumption and network structure are thus determined simultaneously.

\subsection{Arrangement of fixed load operations in batch processes}

For a fixed load operation $i$ in batch processes, Fig. 4(a) shows the representation in Gantt chart. There exists specific time periods for input $\left(t_{1}-t_{2}\right)$ and output $\left(t_{3}-t_{4}\right)$, and the time interval between them is the processing time to achieve the desired effect. The water requirement of operation $i, Q_{i}$ is calculated by Eq. (1), where $m_{i}^{\text {(load) }}$ is the mass load of contaminant to be removed, and $C_{i}^{\text {(in) }}$ and $C_{i}^{\text {(out) }}$ are the concentrations of contaminant in inlet and outlet streams which must not overstep their maximum allowable values, $C_{i, \max }^{\text {(in) }}$ and $C_{i, \max }^{(\text {out })}$. Note that the water requirement and mass load are measured in quantity with unit of $\mathrm{kg}$ or ton instead of flowrate (in $\mathrm{kg} / \mathrm{h}$ or ton/h), as each flowing stream only takes place in a limited time period:

$Q_{i}=m_{i}^{(\text {load })} /\left(C_{i}^{(\text {out })}-C_{i}^{(\text {in })}\right)$

As the aforementioned, the input and output of operation $i$ can be appropriately represented by its corresponding demand $\mathrm{D}_{i}$ and source $S_{i}$. Therefore, as stated in Eqs. (2)-(4), the concentrations of $\mathrm{D}_{i}$ and $\mathrm{S}_{i}$ are identical to the inlet and outlet concentrations of operation $i$, and both quantities of $\mathrm{D}_{i}$ and $\mathrm{S}_{i}$ are equivalent to the water requirement to fulfill operation $i$. The superscripts $\mathrm{D}$ and $\mathrm{S}$ signify demand and source, respectively.

$C_{i}^{(\mathrm{in})}=C_{i}^{\mathrm{D}}$

$C_{i}^{\text {(out) }}=C_{i}^{S}$

$Q_{i}=Q_{i}^{\mathrm{D}}=Q_{i}^{S}$

To minimize the water requirement, the outlet concentration of each fixed load operation is properly set to its maximum allowable value, i.e. the maximum outlet concentration. It is, in fact, a
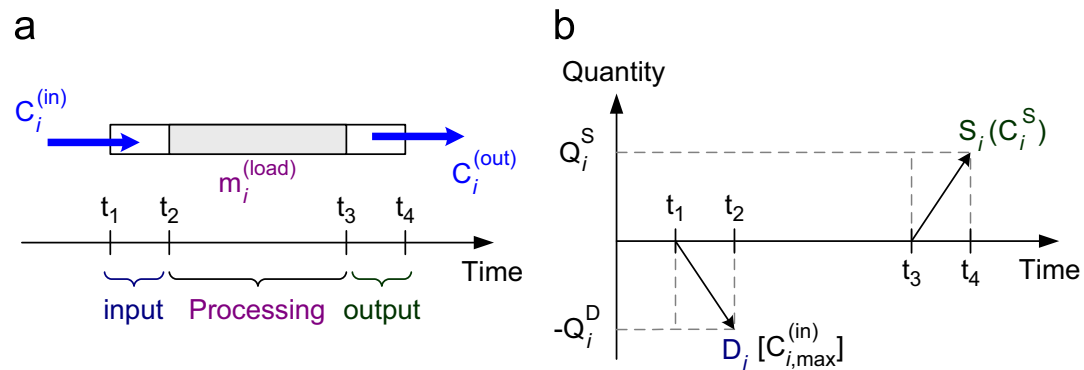

Fig. 4. Representation of a fixed load operation $i$ in batch processes by (a) Gantt chart and (b) quantity-time diagram.

a

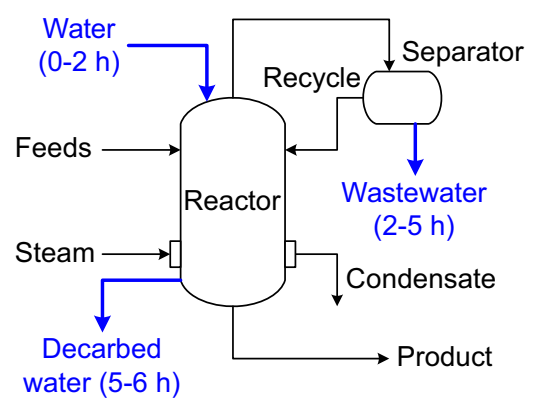

b

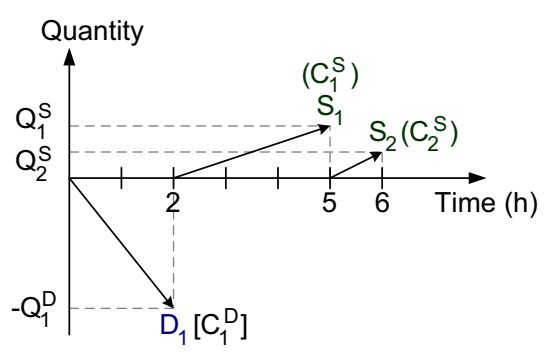


necessary condition for an optimal network design which has been proven by Savelski and Bagajewicz (2000). Before assigning the inlet concentration, we have to check the usability provided there are available sources for reuse. If the concentration of an available source $i$ (from operation $i$ ) is higher than or equal to the maximum allowable outlet concentration of another operation $i^{\prime}, C_{i}^{S} \geqslant C_{i^{\prime}, \max }^{\text {(out) }}$, this source is incapable to pick up any contaminant and unbenefited to be used by operation $i^{\prime}$. On the other hand, if the concentration of source $i$ is located between the maximum allowable inlet and outlet concentrations of operation $i^{\prime}, C_{i^{\prime}, \max }^{\text {(in) }}<C_{i}^{S}<C_{i^{\prime}, \text { max }}^{\text {(out }}$, this source is useful for operation $i^{\prime}$, but may increase the usage of freshwater since the dilution before reuse is required. Moreover, if the concentration of source $i$ is lower than or equal to the maximum allowable inlet concentration of operation $i^{\prime}, C_{i}^{S} \leqslant C_{i^{\prime}, \text { max }}^{(\text {in) }}$, this source can be used safely to fulfill operation $i^{\prime}$ without any misgiving. Consequently, some useless sources will be eliminated by the above criterion and discharged directly to the environment. In general, it is reasonable to raise the inlet concentration close to its maximum allowable value to enhance the possibility of water recovery. After resolving the inlet and outlet concentrations, the water requirement of each fixed load operation as well as the quantities of its corresponding demand and source are established immediately. Sometimes there will be surplus of the relatively clean sources after finishing the stream allocation, hence we can revise the design by moderately lowering the inlet concentrations of fixed load operations to result the smaller unit sizes and less capital cost. As the larger difference between inlet and outlet concentrations causes the smaller amount of flow through the process unit, which agrees with Eq. (1).

By plotting the established quantities of demand $i$ and source $i$ $\left(D_{i}\right.$ and $S_{i}$ ) versus time, as shown in Fig. $4(\mathrm{~b})$, the behavior of batch operation $i$ is represented more clearly. Note that the quantity of available source is expressed in positive value, whereas the quantity of demand to be satisfied is displayed in negative value. In addition, the actual concentration of source $i\left(C_{i}^{S}\right)$ and the maximum allowable concentration of demand $i\left(C_{i, \max }^{(\mathrm{in})}\right)$ may be marked if necessary during the analysis.

\subsection{Arrangement of fixed quantity operations in batch processes}

As it is more precise to measure water streams with the quantity of flow in batch processes, we prefer to name a fixed flowrate operation as a fixed "quantity" operation. For the representation of fixed quantity operations, a batch reactor system shown in Fig. 5(a) is provided as an example. There are three relevant aqueous streams passing in and out of the system within different time periods, which include water intake $(0-2 \mathrm{~h})$, wastewater discharge $(2-5 \mathrm{~h})$ and the decarbed water (5-6h). Definitely, each inlet and outlet streams can be represented as individual water demand $D_{j}$ or water source $S_{k}$, where subscripts $j$ and $k$ are the indices of demands and sources for the fixed quantity operations. Therefore, the only input (water intake) is denoted by $\mathrm{D}_{1}$ and two outputs (wastewater and decarbed water) are denoted by $S_{1}$ and $S_{2}$, respectively. With existing period, quantity and limiting concentration of each inlet/outlet stream, the behavior of batch reactor system is presented by the quantity-time diagram as shown in Fig. 5(b).

Since the quantity of each demand or source is specified in a fixed quantity operation, changing the inlet concentration will not alter the requirement of water due to the problem definition. Therefore, it tends to maximize the inlet concentration to not only exploit the wastewater as far as possible, but also reserve the cleaner sources for the other operations. This way can be done validly by the principle of nearest neighbors (Prakash and Shenoy, 2005) with available sources.

\section{Case study}

To illustrate the application of proposed approach to network design in batch processes, a hypothetical example which comprises five water-using operations in a single batch period is investigated.

Table 1

Problem specification for the case study

\begin{tabular}{|c|c|c|c|c|c|c|}
\hline \multirow[t]{2}{*}{ Operation } & \multicolumn{2}{|c|}{ Time (h) } & \multirow{2}{*}{\multicolumn{2}{|c|}{$\begin{array}{l}C_{i, \max }^{\text {(in) }} \\
\text { (kg salt } / \mathrm{kg} \text { water) }\end{array}$}} & \multirow[t]{2}{*}{$m_{i}^{\text {(load) }}$ (ton) } & \multirow[t]{2}{*}{ Minimum requirement (ton) } \\
\hline & input & $\overline{\text { output }}$ & & & & \\
\hline 1 & $0.0-1.0$ & $4.0-5.0$ & 0.0 & 0.2 & 4.0 & - \\
\hline 2 & $0.0-0.5$ & $4.5-5.0$ & 0.25 & 0.5 & 4.0 & - \\
\hline 3 & $5.0-6.5$ & $5.0-6.5$ & 0.1 & - & 0.0 & 15 \\
\hline 4 & $2.0-2.5$ & $6.5-7.0$ & 0.25 & 0.4 & 3.6 & - \\
\hline 5 & $7.0-8.5$ & $7.0-8.5$ & 0.1 & - & 0.3 & 15 \\
\hline
\end{tabular}

a

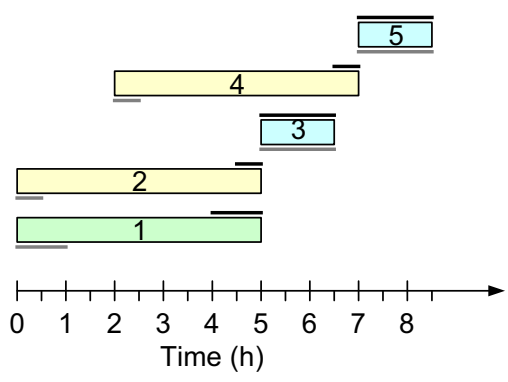

b

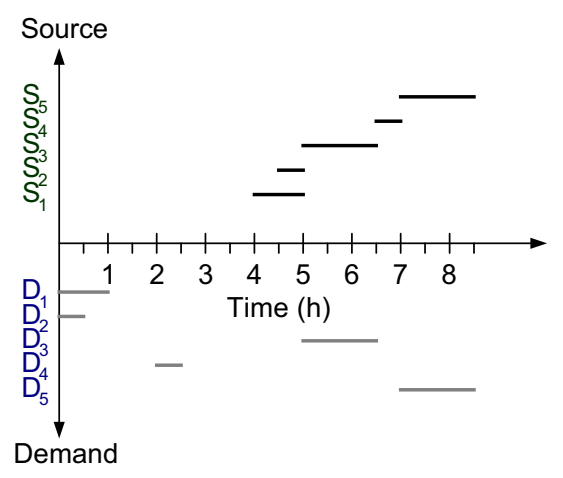

Fig. 6. Gantt chart of (a) all water-using operations and (b) all water demands/sources for the case study. 
a

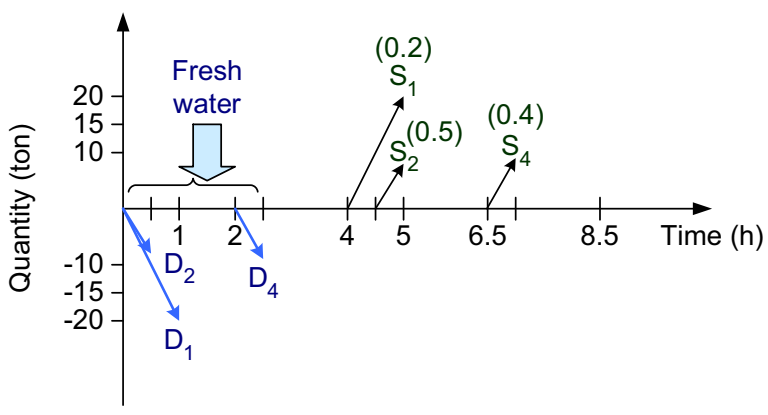

C

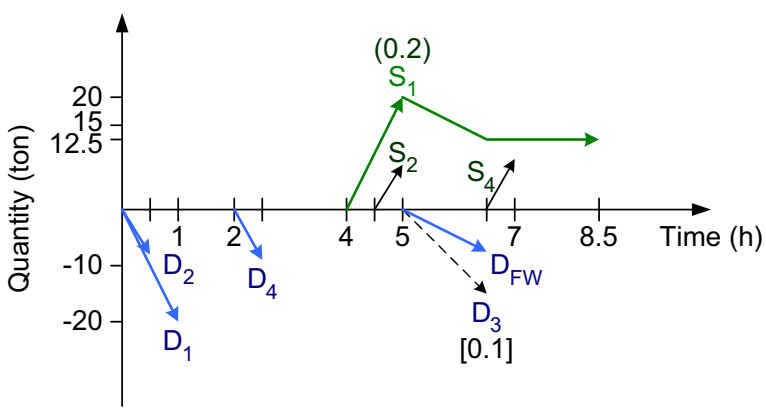

e

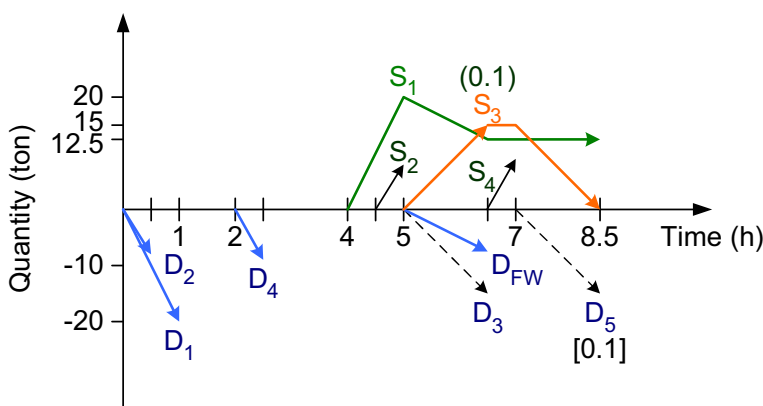

b

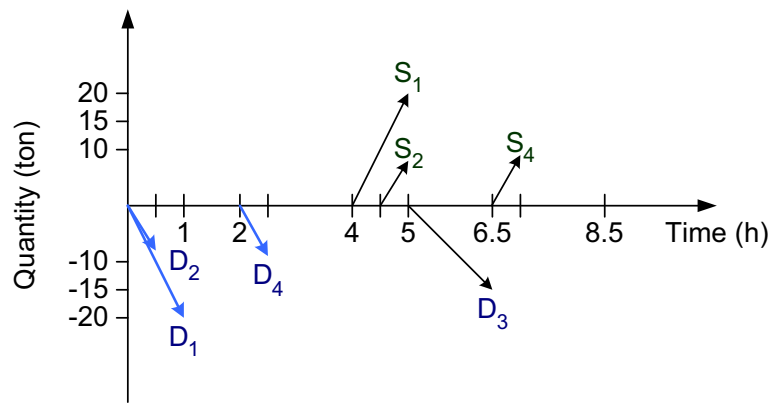

d

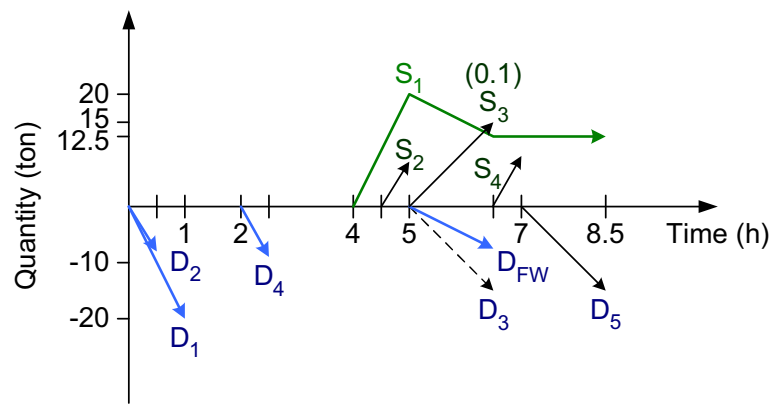

f

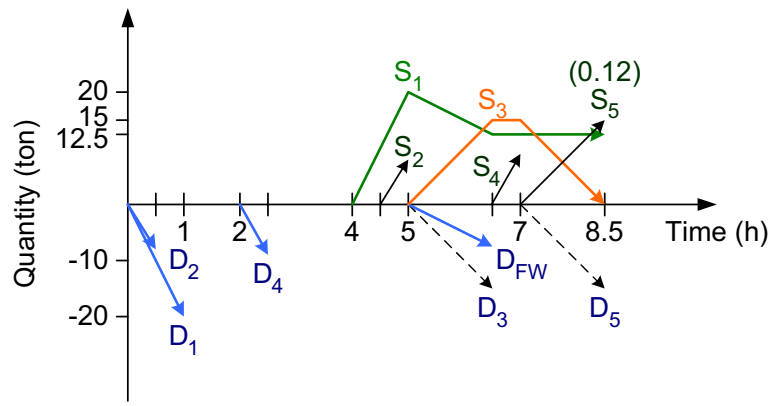

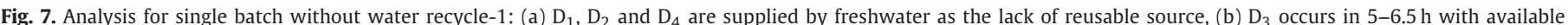

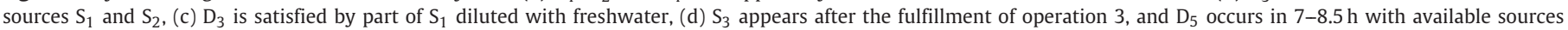
$S_{1}, S_{2}, S_{3}$ and $S_{4}$, (e) $D_{5}$ is satisfied by $S_{3}$, and then (f) $S_{5}$ appears after the fulfillment of operation 5 .

a

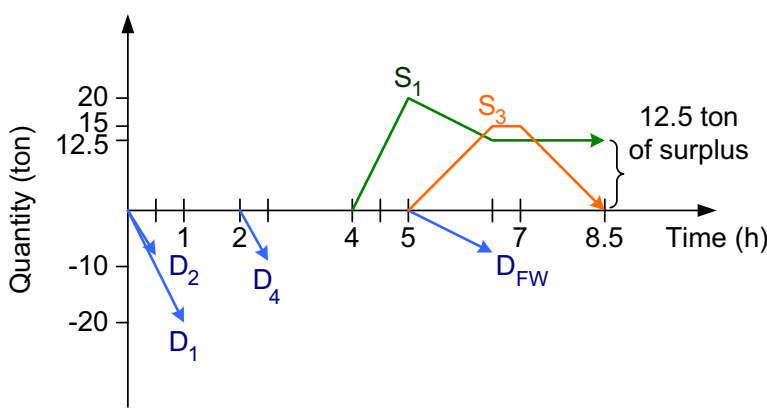

b

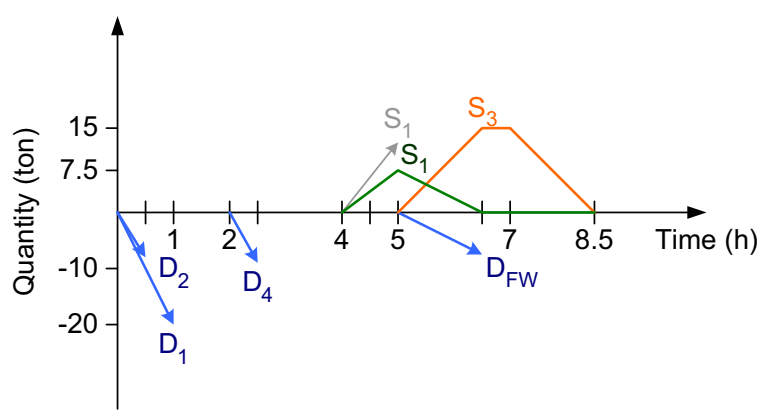

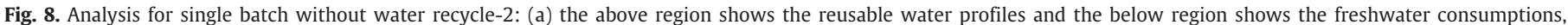
and furthermore (b) the storage policy is determined according to the reusable water profiles.

Processing data for this case study are given in Table 1, where all operations are formulated as fixed load operations and take place in their respective mass transfer units. It is obvious that the contaminant loads in operations 3 and 5 are quite small (even no contaminant), but the minimum water requirements are specified to perform effective working. Therefore, these two operations can be 
treated as fixed quantity operations. Also note that the maximum outlet concentrations for both operations 3 and 5 are insignificant as they have been considered in water requirements.

Fig. 6(a) shows the Gantt chart of all water-using operations in this case study. The duration of each batch operation is expressed by a color bar. Moreover, time periods for input and output are indicated, respectively, by the solid lines under and over the color bar. It can be found that operations 1, 2 and 4 have definite processing times between input and output periods, which means those operations are processed in a "completely batch" mode. As to operations 3 and 5, the processing times are omitted due to the rapid effects, and such type of operations can be termed as a "semi-continuous" operation because the input and output seem to take place simultaneously in a certain time period. Fig. 6(b) shows that all inlet and outlet streams of water-using operations are represented as water demands and sources separately. For example, operation 1 is divided to its corresponding demand $\mathrm{D}_{1}$ and source $S_{1}$, and operation 2 is regarded as $\mathrm{D}_{2}$ and $\mathrm{S}_{2}$, and so on.

Prior to the exploration of water reuse/recycle, the base case in which all operations are fulfilled by freshwater is identified for the
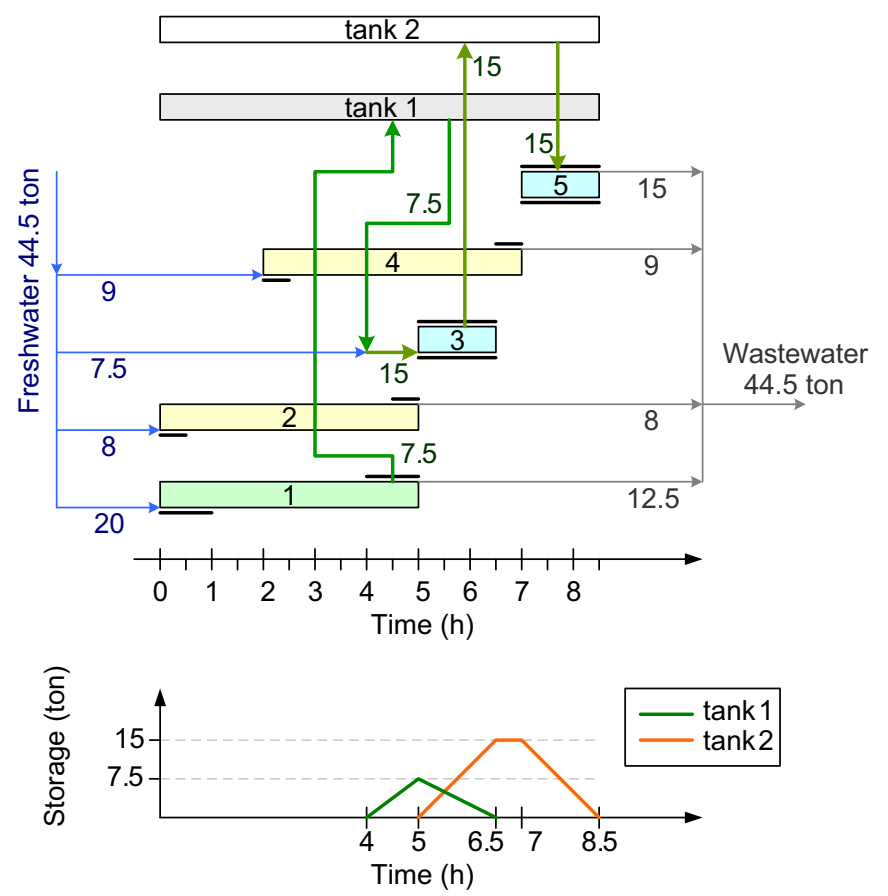

Fig. 9. Resultant network of single batch without water recycle: two storage tanks.

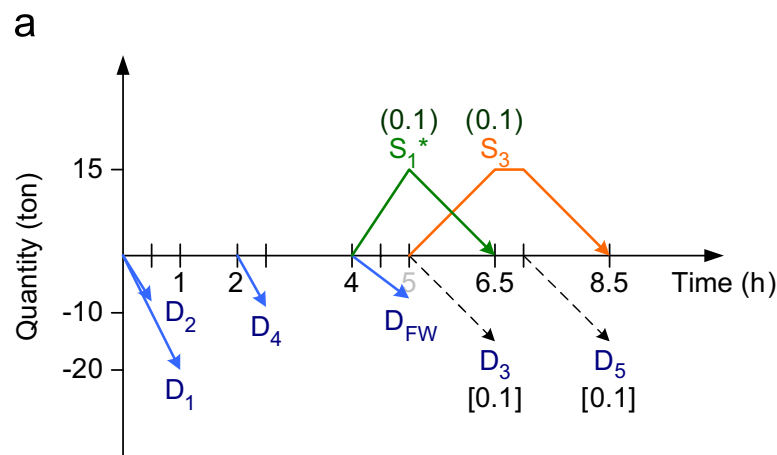

follow-up analyses. Since the freshwater is assumed to be free of contaminant, the inlet concentration to each operation is zero. About the fixed load operations 1,2 and 4, it is reasonable to fix the outlet concentration to its maximum value for minimum water requirement, and then the amount of water required can be calculated by Eq. (1). On the other hand, both operations 3 and 5 have a specified water requirement as 15 ton. Therefore, the freshwater target is

$4 /(0.2-0)+4 /(0.5-0)+3.6 /(0.4-0)+15+15=67$ ton

in a single batch period ( $8.5 \mathrm{~h})$.

\subsection{Analysis for single batch}

\subsubsection{Water network without direct recycle}

Firstly, all demands and sources are arranged in order according to the starting time:

$$
\left\{D_{1} / D_{2}, D_{4}, S_{1}, S_{2}, D_{3}, S_{3}, S_{4}, D_{5}, S_{5}\right\}
$$

Then the analysis is carried out by the sequence of stream appearing. It is worthy to note that although the appearances of $\mathrm{D}_{3}$ and $S_{3}$ seem at the same time, as well as $D_{5}$ and $S_{5}$, the demand (input) should be satisfied before the source generation (output)
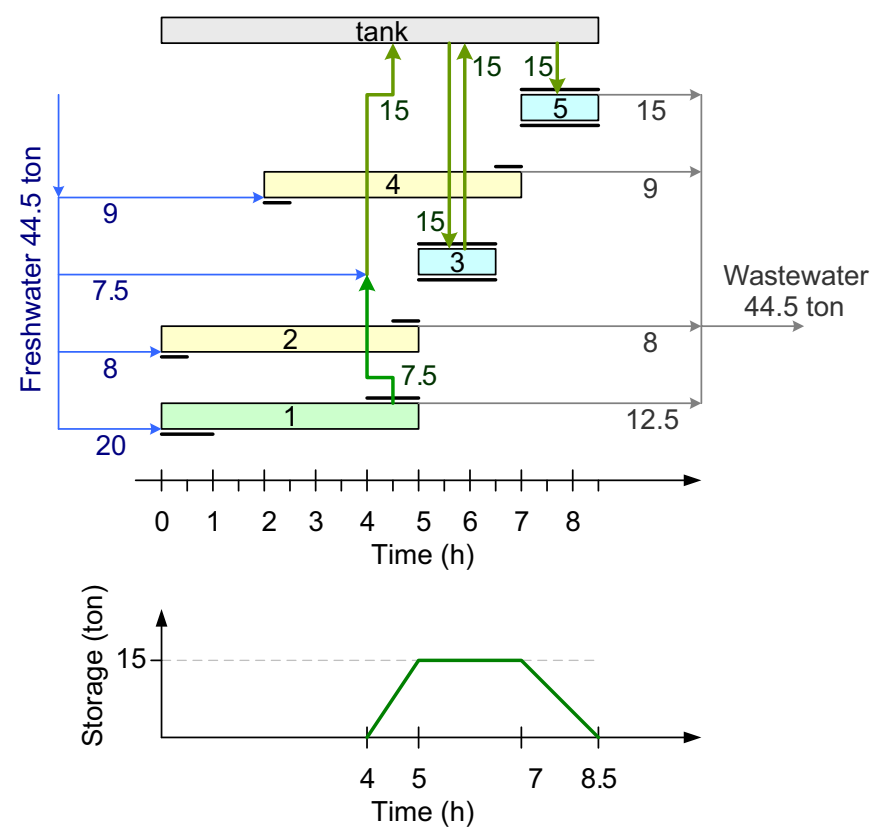

Fig. 11. Resultant network of single batch without water recycle: one storage tank.

b

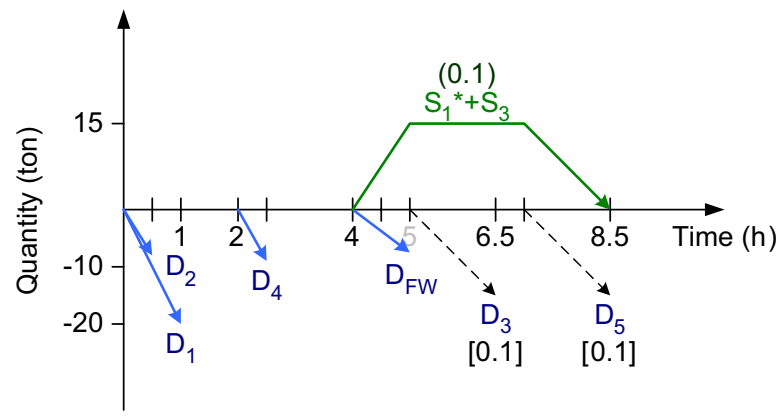

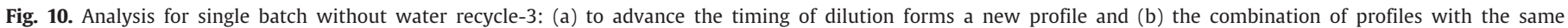
concentration. 
a

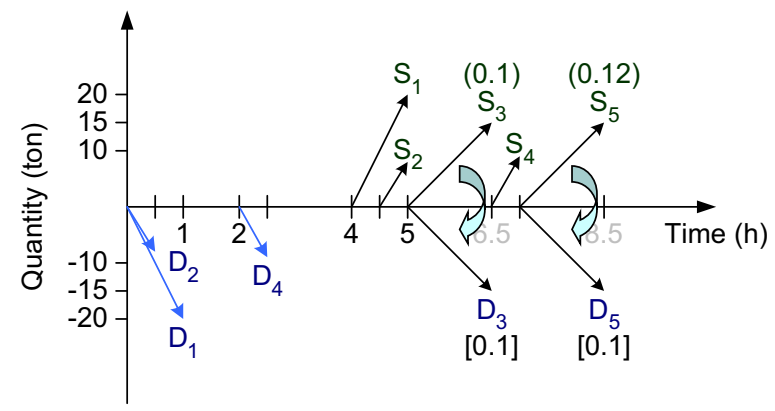

b

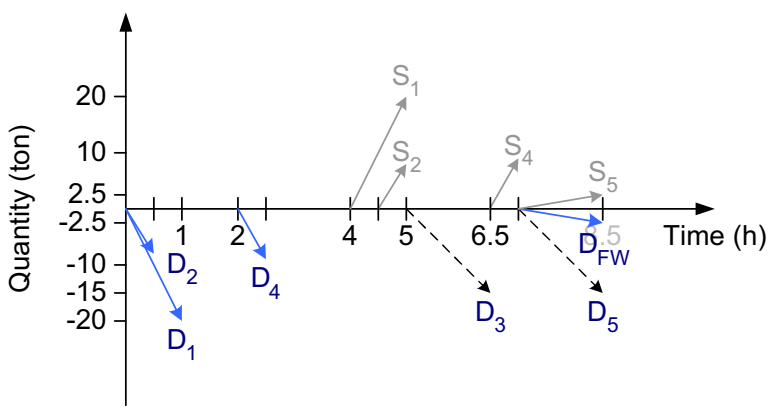

Fig. 12. Analysis for single batch with water recycle: (a) consider a better way of water recovery and (b) operations 3 and 5 are fulfilled by direct water recycle.

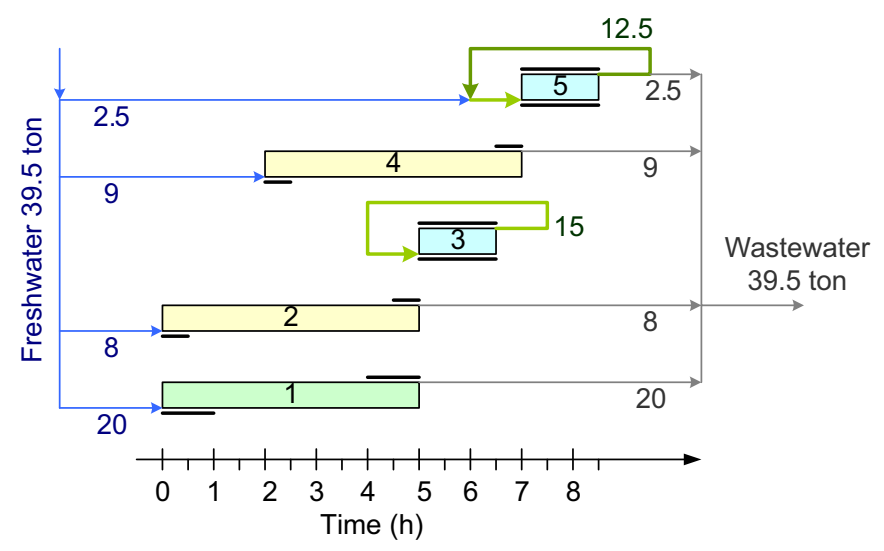

Fig. 13. Resultant network of single batch with water recycle.

because they belong to identical process. For that reason, we consider $D_{3}$ prior to $S_{3}$ and $D_{5}$ ahead of $S_{5}$. Obviously, there is no available source exists when the periods that $D_{1}(0-1 h), D_{2}(0-0.5 h)$ and $D_{4}$ $(2-2.5 \mathrm{~h})$ occur, hence only freshwater could be supplied to operations 1,2 and 4 as the input, i.e. $C_{1}^{(\text {in) }}=0, C_{2}^{(\text {in) }}=0$ and $C_{4}^{(\text {in) }}=0$. By replacing the outlet concentrations with maximum allowable values as the necessary condition of optimality, $C_{1}^{\text {(out) }}=0.2, C_{2}^{\text {(out) }}=0.5$ and $C_{4}^{\text {(out) }}=0.4$, Eq. (1) gives the water requirements of these fixed load operations: $Q_{1}=20$ ton, $Q_{2}=8$ ton and $Q_{4}=9$ ton. From Eq. (4), the quantity of demands and sources in operations 1,2 and 4 are also derived as $Q_{1}^{\mathrm{D}}=Q_{1}^{S}=20$ ton, $Q_{2}^{\mathrm{D}}=Q_{2}^{S}=8$ ton and $Q_{4}^{\mathrm{D}}=Q_{4}^{\mathrm{S}}=9$ ton. Hence the quantities of encountered demands $D_{1}, D_{2}, D_{4}$ and later generated sources $S_{1}, S_{2}, S_{4}$ are established and have been plotted on the quantity-time diagram in Fig. 7(a), where the light blue color indicates the demand for freshwater. The concentrations of $S_{1}, S_{2}$ and $\mathrm{S}_{4}$ can be obtained from Eq. (3) that are $0.2,0.5$ and $0.4 \mathrm{~kg}$ salt $/ \mathrm{kg}$ water, respectively.

As shown in Fig. 7(b), demand $\mathrm{D}_{3}$ occurs in the 5-6.5 h time interval. Sources $S_{1}\left(20\right.$ ton) and $S_{2}$ ( 8 ton) are available for $D_{3}$ at present, but $S_{4}$ ( 9 ton) is unavailable yet due to the later appearance. The quantity of $D_{3}$ is equal to the water requirement for operation 3 which is specified as 15 ton. For the specified water requirement, one would like to treat operation 3 as a fixed quantity operation, that is, to maximize the inlet concentration by any means. Since the maximum allowable concentration of $D_{3}$ is $0.1 \mathrm{~kg}$ salt $/ \mathrm{kg}$ water, the nearest neighbor sources are freshwater and $S_{1}$. The required quantities of freshwater and $S_{1}$ are both 7.5 ton, which make up the concentration to $0.1 \mathrm{~kg}$ salt $/ \mathrm{kg}$ water. Fig. $7(\mathrm{c})$ shows that $\mathrm{D}_{3}$ is satisfied by $S_{1}$ diluted with freshwater, where 7.5 ton of $S_{1}$ is consumed with a surplus of 12.5 ton. Moreover, the requirement of dilution is equivalent to an additional demand $D_{F W}$ for freshwater in the 5-6.5 h time interval. Note that the arrow of $D_{3}$ is transformed from a solid line to a dashed one, which indicates that the demand is fulfilled by water reuse.

After the fulfillment of operation 3, source $S_{3}$ appears in Fig. 7(d). With the specified water requirement $\left(Q_{3}=15\right.$ ton $)$ and the assigned inlet concentration $\left(C_{3}^{(\mathrm{in})}=0.1\right)$, Eqs. (1)-(3) give that the concentration of $\mathrm{S}_{3}$ is $0.1 \mathrm{~kg}$ salt $/ \mathrm{kg}$ water. Also shown in Fig. 7(d), demand $\mathrm{D}_{5}$ occurs in the $7-8.5 \mathrm{~h}$ time interval with the specified quantity as 15 ton, which forms another fixed quantity case. Now sources $S_{1}$ (12.5 ton), $S_{2}$ ( 8 ton), $S_{3}$ (15 ton) and $S_{4}$ (9 ton) are available for $D_{5}$. Since the concentration of $S_{3}$ is exactly equal to the maximum allowable value of $D_{5}$ and the quantity of $S_{3}$ is also sufficient for $D_{5}$, it is reasonable to choose $S_{3}$ for the fulfillment of operation 5 . Fig. $7(e)$ shows that $S_{3}$ is completely consumed to satisfy $D_{5}$, and subsequently source $S_{5}$ appears in Fig. 7(f). With known water requirement $\left(Q_{5}=15\right.$ ton $)$ and concentration $\left(C_{5}^{(\text {in })}=0.1\right)$, Eqs. (1)-(3) give that the concentration of $S_{5}$ is $0.12 \mathrm{~kg}$ salt $/ \mathrm{kg}$ water.

Figs. 7(a)-(f) exhaustively present the use of quantity-time diagram for the analysis in a batch period. As to the outcome of stream allocation, it can be seen that sources $S_{1}$ and $S_{3}$ have been reused to lower the freshwater consumption, whereas other sources $S_{2}, S_{4}$ and $\mathrm{S}_{5}$ are unused and then become the wastewater to be discharged. However, these reusable sources cannot be directly utilized due to the unoverlapping durations of $S_{1}$ and $D_{3}$, as well as $S_{3}$ and $D_{5}$. Such time gaps between source and demand explicitly point out the necessity for storage facilities. In Fig. 8(a), by ignoring the demands that satisfied by water reuse (in dashed lines), the below region of quantity-time diagram offers the requirement for freshwater. Consequently, the overall freshwater expenditure on a single batch is amounted to $Q_{1}+Q_{2}+Q_{4}+7.5=44.5$ ton. Furthermore, with the omission of unused sources, the above region shows the reusable water profiles which indicate that two storage tanks are required to store $S_{1}$ and $S_{3}$ separately to avoid the degradation of quality. Since only part of $S_{1}$ has been consumed, 7.5 ton of $S_{1}$ to be stored is enough and 12.5 ton of surplus (in gray color) will be discharged, as shown in Fig. 8(b). According to the shifted profiles, the required capacity of storage tanks are 7.5 ton for $S_{1}$ and 15 ton for $S_{3}$, respectively. Fig. 9 shows the resulting network structure: operations 1, 2 and 4 are supplied by freshwater. Part of used water from operation 1 is stored in tank 1 and then diluted with freshwater before supplied to operation 3 . All of the used water from operation 3 is stored in tank 2 and released later for operation 5 .

Different to the previous result, Figs. 10(a) and (b) show another possible strategy to implement the batch water system. As shown in Fig. 10(a), similarly, 7.5 ton of $S_{1}$ diluted with 7.5 ton of freshwater is used to supply $\mathrm{D}_{3}$ but the timing of dilution is advanced from 5-6.5 h to $4-5 \mathrm{~h}$. Here $\mathrm{S}_{1}$ is diluted before entering the tank; in other words, the source in storage is the diluted $S_{1}$ rather than the original output of operation 1 . The diluted $S_{1}$ forms a new source named as $S_{1}^{*}$ with 
a

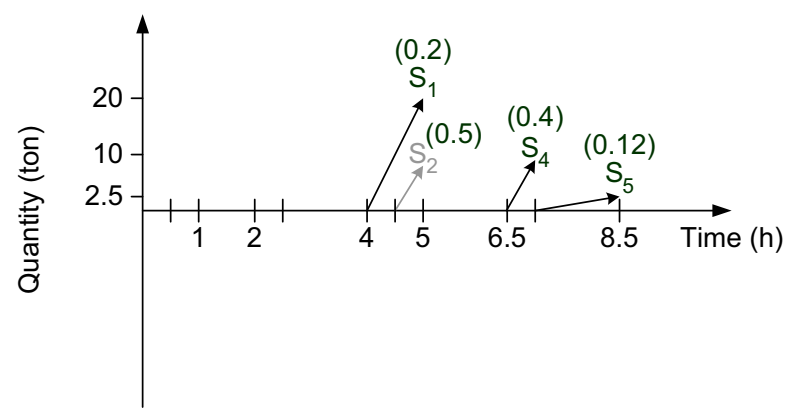

C

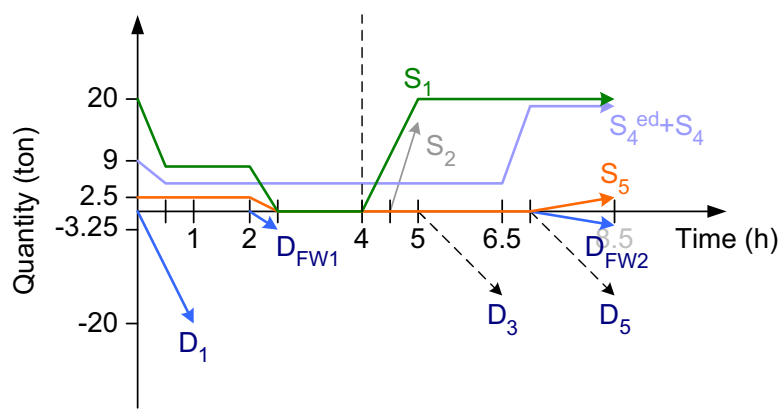

b

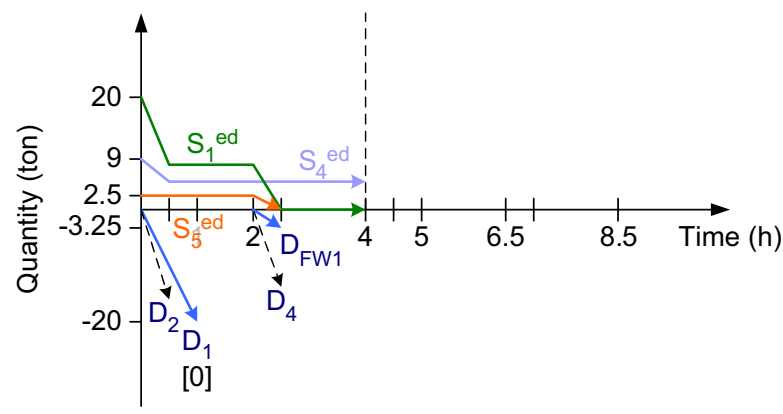

d

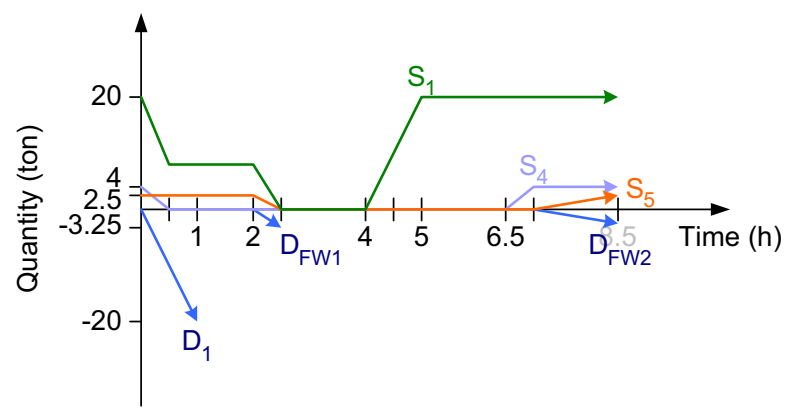

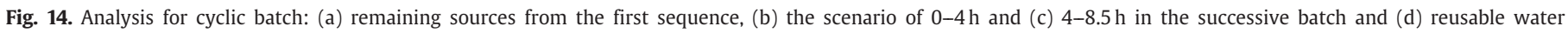
profiles under decided storage policy.
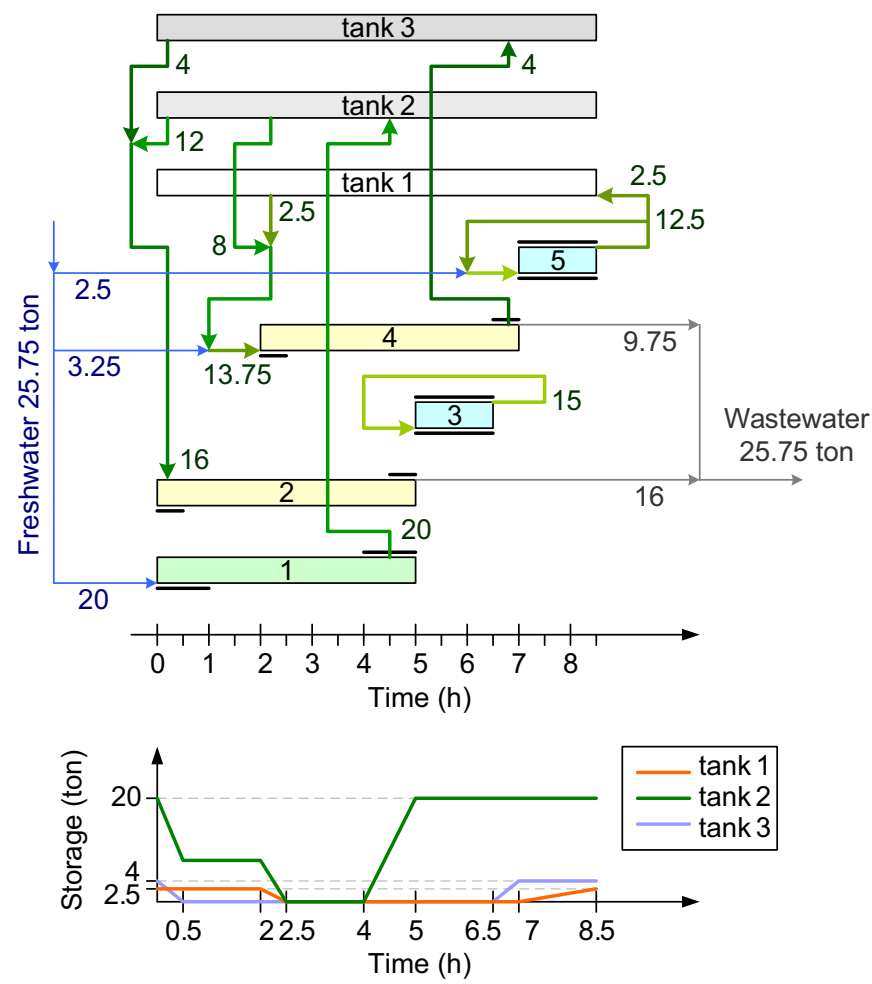

Fig. 15. Resultant network of cyclic batch: three storage tanks.

the quantity of 15 ton and the concentration of $0.1 \mathrm{~kg}$ salt $/ \mathrm{kg}$ water. After satisfying $D_{3}$ by $S_{1}^{*}$, the generated source $S_{3}$ can be stored and then used to supply demand $D_{5}$. Note that the remaining $S_{1}$ (not being diluted) will be discharged like the other unused sources
$\mathrm{S}_{2}, \mathrm{~S}_{4}$ and $\mathrm{S}_{5}$ (omitted from the figure). Consequently, the overall freshwater expenditure is still 44.5 ton for a single batch. Since $S_{1}^{*}$ and $S_{3}$ have the same concentration, it is workable to collect them together. Fig. 10(b) shows the combination of two reusable sources, and the resulting profile signifies that only one storage tank with a capacity of 15 ton is sufficient to obtain the same amount of water recovery. Fig. 11 shows the resultant network design which looks better because the less number of tanks implies the lower cost in storage facilities.

\subsubsection{Water network with reuse and recycle}

By way of the preliminary design, we obtain an acceptable result which corresponds to a $33.58 \%$ reduction in freshwater expenditure. Since the analysis is strictly performed in compliance with the order of stream appearing, the case of direct water recycle is excluded. Although the outlet stream appears later than the fulfillment of inlet stream in a normal mass transfer operation, the time delay may be transient when the operation is processed in a semi-continuous mode. In practice, it would be possible to feed such operation by its own output after the initialization with a negligible amount of water, where the negligible amount corresponds to the required volume to fill up the piping system. Under this consideration, one can take the demand and source in both operations 3 and 5 as absolutely simultaneous and the sequence of stream is rearranged to:

$\left\{D_{1} / D_{2}, D_{4}, S_{1}, S_{2}, D_{3} / S_{3}, S_{4}, D_{5} / S_{5}\right\}$

As shown in Figs. 12(a) and (b), operations 1, 2, and 4 are fulfilled by freshwater (20, 8 and 9 ton, respectively) as the lack of reusable source over the first four hours. For demand $\mathrm{D}_{3}$ occurs in the $5-6.5 \mathrm{~h}$ time interval, sources $S_{1}, S_{2}$ and $S_{3}$ are available at present. Because of no contaminant to be removed in operation 3 , the concentration of $S_{3}$ is identical to that of $D_{3}$ which is fixed on its maximum value, $0.1 \mathrm{~kg}$ salt $/ \mathrm{kg}$ water. Therefore, $S_{3}$ is chosen to satisfy $D_{3}$ and then operation 3 is fulfilled by total recycle. With regards to demand $D_{5}$ 
a

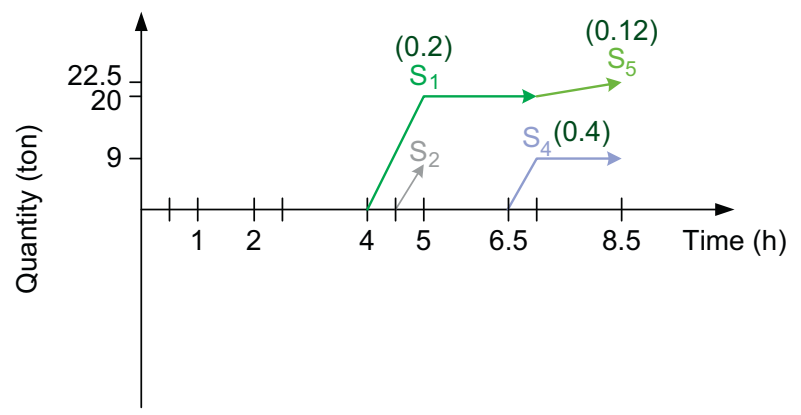

C

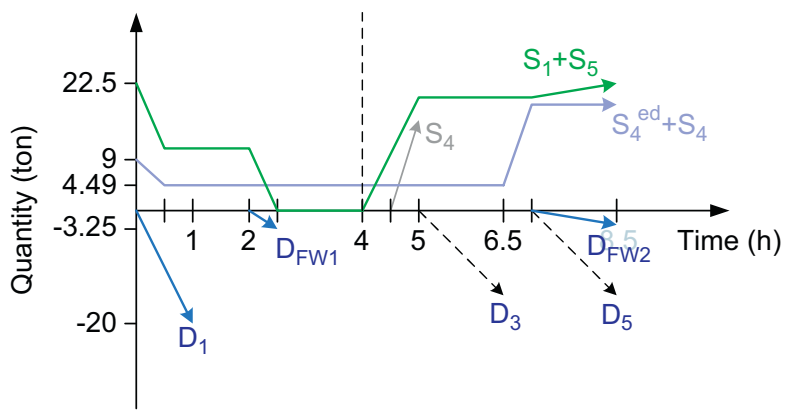

b

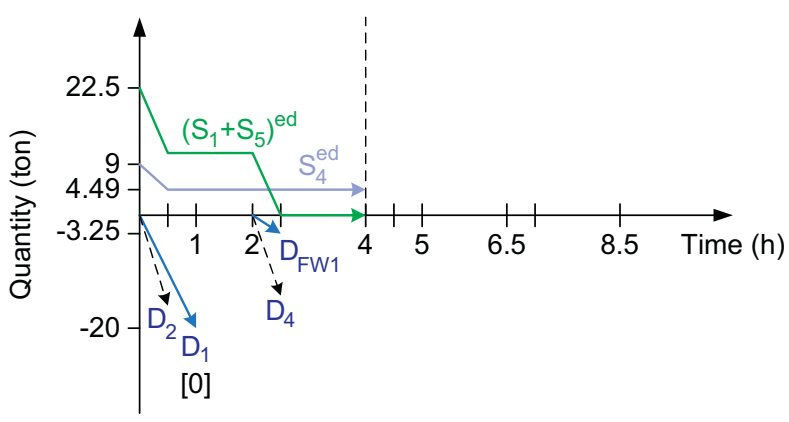

d

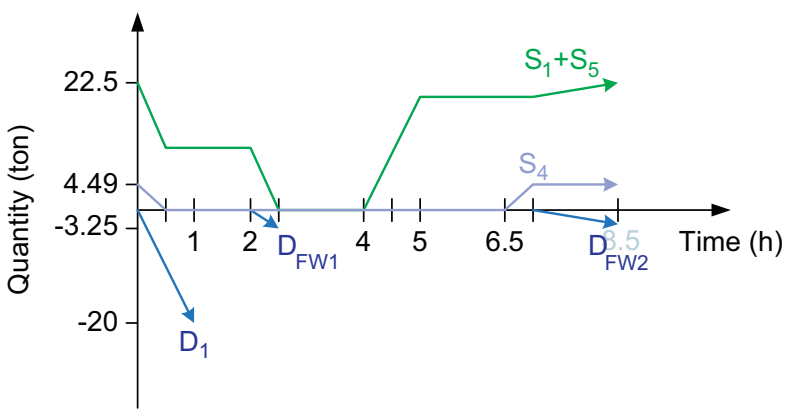

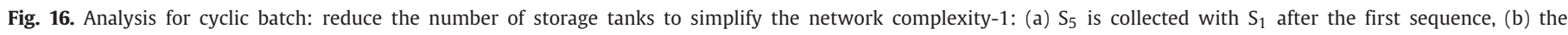
scenario of $0-4 \mathrm{~h}$ and (c) $4-8.5 \mathrm{~h}$ in the successive batch and (d) reusable water profiles under decided storage policy.
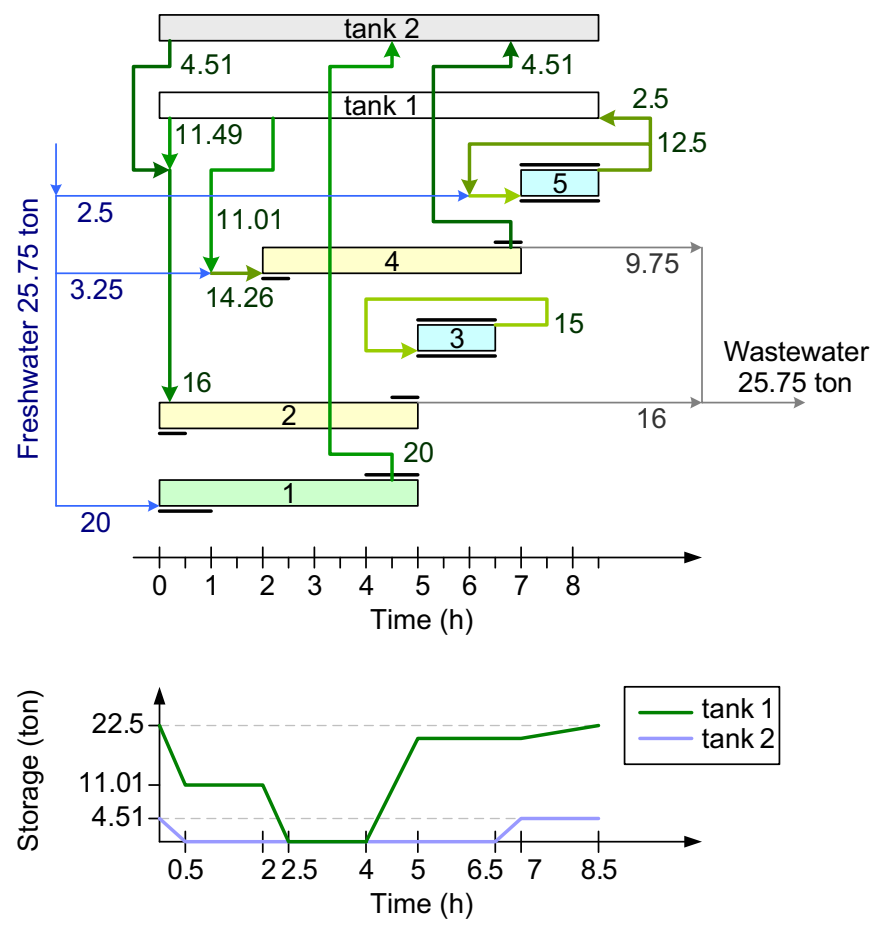

Fig. 17. Resultant network of cyclic batch: two storage tanks.

occurs in the $7-8.5 \mathrm{~h}$ time interval, the nearest neighbors become freshwater and $S_{5}$ since $S_{3}$ is totally consumed by $D_{3}$. Note that the concentration of $D_{5}$ is fixed on its maximum value, $0.1 \mathrm{~kg}$ salt $/ \mathrm{kg}$ water and the concentration of $S_{5}$ is calculated as $0.12 \mathrm{~kg}$ salt $/ \mathrm{kg}$ water by Eqs. (1)-(3) with specified water requirement and given contaminant load. Thus operation 5 is fulfilled by partial recycle, i.e. 12.5 ton of $\mathrm{S}_{5}$ and 2.5 ton of freshwater, due to the inlet restriction on concentration. The 2.5 ton of surplus $S_{5}$ is then discharged together with the other unused sources $S_{1}, S_{2}$ and $S_{4}$. Consequently, the overall freshwater expenditure becomes $Q_{1}+Q_{2}+Q_{4}+2.5=39.5$ ton, and it seems no need of storage tank if we ignore the amount of water for initialization. Fig. 13 shows the renewed design with further consideration, where water recycling in operations 3 and 5 is taken as a possible way to improve the water recovery and also reduce the requirement of storage facilities.

\subsection{Analysis for cyclic batch}

It is common in industry that more than one batch to be operated as a multi-stage production to achieve the required capacity or meet the specified order for product. This kind of operating mode can be termed as "cyclic batch", which implies that consecutive batches are repeated with the same schedule in an extended time horizon. The difference of cyclic batch to the single batch case is obvious that the surplus water from previous batch could be collected for the use in next batch if profitable. Therefore, the later sources can now be used to feed the earlier demands in the time scale of batch cycle.

\subsubsection{Determine the freshwater expenditure}

The first sequence of cyclic operation is equivalent to a single batch through a relatively short time horizon, and therefore the analysis for cyclic batch in this section will base on the result of single batch in Figs. 12 and 13. For the successive batch, Fig. 14(a) shows the remaining sources from the first sequence, including $S_{1}$ (20 ton), $\mathrm{S}_{2}$ (8 ton), $\mathrm{S}_{4}$ (9 ton) and $\mathrm{S}_{5}$ (2.5 ton). The concentrations of those sources are $0.2,0.5,0.4$ and $0.12 \mathrm{~kg}$ salt $/ \mathrm{kg}$ water, respectively. In accordance, there will be more sources available in the successive batch, and it also enhances the opportunities of water reuse. Then we attempted to analyze the problem once again with different condition for the batch next to the first sequence. Fig. 14(b) shows the 
a

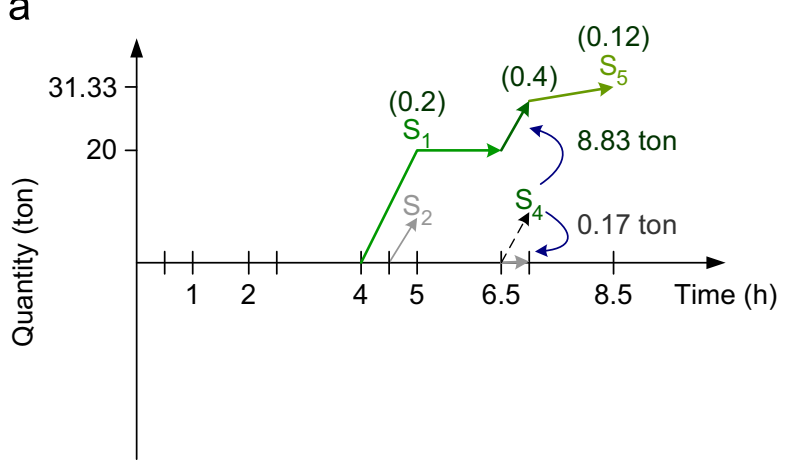

b

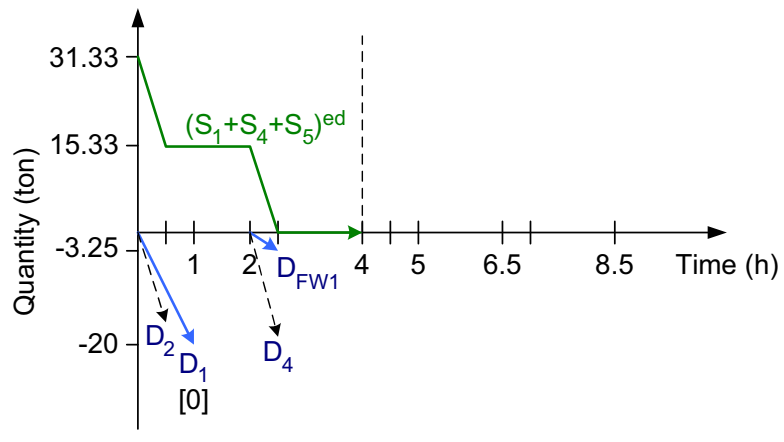

C

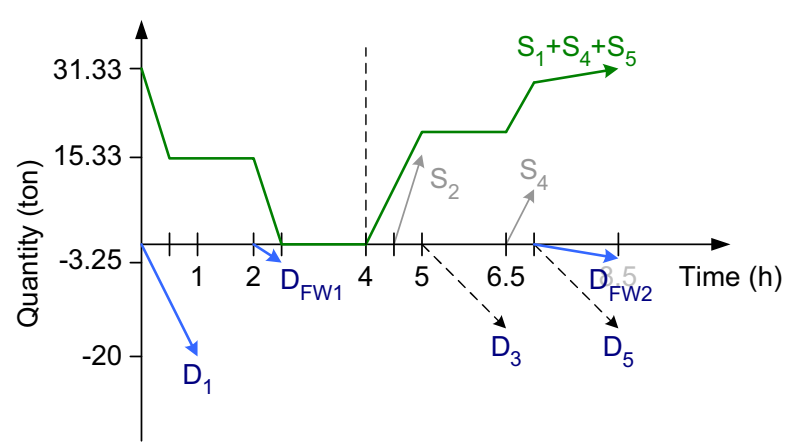

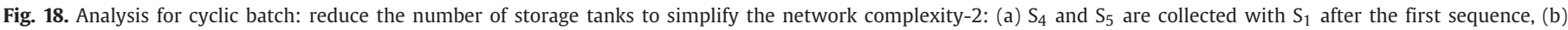
the scenario of $0-4 \mathrm{~h}$ and (c) $4-8.5 \mathrm{~h}$ in the successive batch.
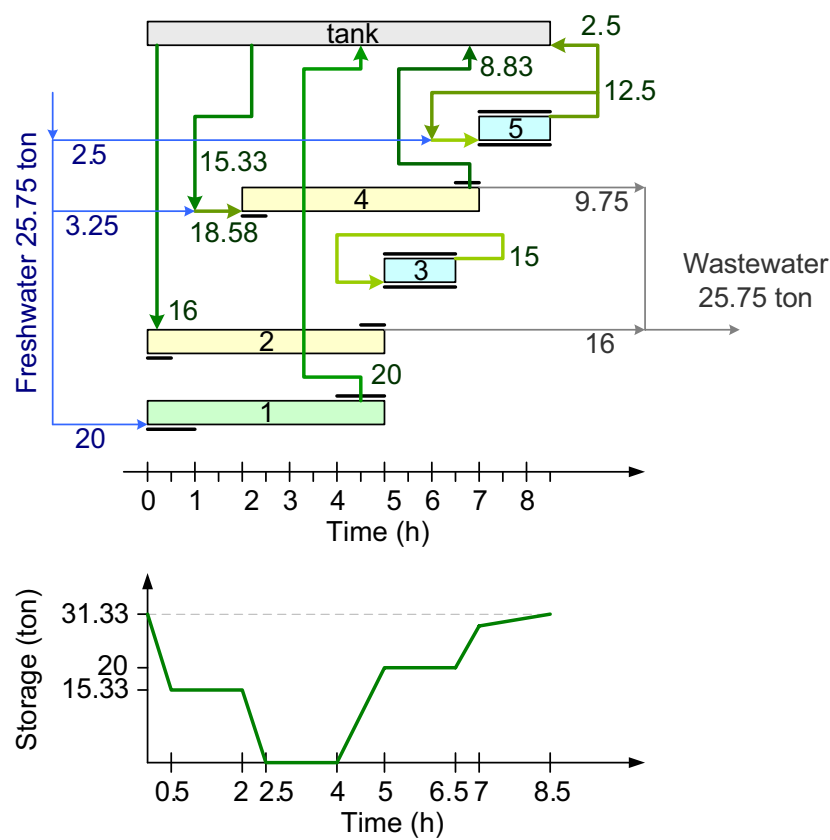

Fig. 19. Resultant network of cyclic batch: one storage tank.

scenario of the $0-4 \mathrm{~h}$ time interval in the successive batch, where the superscript "ed" is used to denote the surplus source from previous batch. As the maximum inlet concentration of operation 1 is zero, it can be only fulfilled by freshwater, i.e. $C_{1}^{(\text {in) }}=0$. By setting the outlet concentration to its maximum value $\left(C_{1}^{\text {(out) }}=0.2\right)$, Eq. (1) gives the water requirement $Q_{1}$ is 20 ton. Hence 20 ton of freshwater is required to satisfy $\mathrm{D}_{1}$. On the other hand, operations 2 and 4 can be fulfilled by water reuse to lower the freshwater consumption because of the looser restriction on inlet concentration. For operation 2 , as the foregoing, it is reasonable to raise the inlet concentration to enhance the possibility of water recovery. Besides, sources $S_{1}^{\text {ed }}$ and $\mathrm{S}_{4}^{\text {ed }}$ have the higher priority than $\mathrm{S}_{5}^{\text {ed }}$ to be reused. $\mathrm{S}_{2}^{\text {ed }}$ is ignored as a choice because its concentration is equal to the maximum outlet concentration of operation 2 ( $0.5 \mathrm{~kg}$ salt $/ \mathrm{kg}$ water), which means the source has no help to pick up the contaminant. By setting both inlet and outlet concentrations of operation 2 on their maximum allowable values $\left(C_{2}^{\text {(in) }}=0.25\right.$ and $C_{2}^{\text {(out) }}=0.5$ ), Eq. (1) gives the water requirement is 16 ton so we can use 12 ton of $S_{1}^{\text {ed }}$ and 4 ton of $S_{4}^{\text {ed }}$ to satisfy $\mathrm{D}_{2}$.

Subsequently, we choose the remaining $S_{1}^{\text {ed }}$ ( 8 ton) and $S_{5}^{\text {ed }}$ ( 2.5 ton) to fulfill operation 4 . $S_{2}^{\text {ed }}$ and $S_{4}^{\text {ed }}$ are excluded from the choice because their concentrations are both higher than or equal to the maximum outlet concentration of operation $4(0.4 \mathrm{~kg}$ salt $/ \mathrm{kg}$ water). By setting $C_{4}^{\text {(out) }}=0.4$, Eq. (1) gives that 8 ton of $S_{1}^{\text {ed }}$ and 2.5 ton of $S_{5}^{\text {ed }}$ can pick up 1.6 and 0.7 ton of contaminant, respectively. However, the contaminant load to be removed in operation 4 is 3.6 ton, which means only the remaining $S_{1}^{\text {ed }}$ and $S_{5}^{\text {ed }}$ is not sufficient to satisfy $\mathrm{D}_{4}$. Still 3.25 ton of additional freshwater is required to remove the left contaminant, as denoted by $\mathrm{D}_{F W 1}$. Therefore, $8+2.5+3.25=13.75$ ton of water with the concentration of $0.138 \mathrm{~kg}$ salt $/ \mathrm{kg}$ water is supplied to operation 4 . After satisfying $\mathrm{D}_{2}$ and $\mathrm{D}_{4}$, $\mathrm{S}_{1}^{\text {ed }}$ and $\mathrm{S}_{5}^{\text {ed }}$ are exhausted and $\mathrm{S}_{4}^{\text {ed }}$ has a surplus of 5 ton. Besides, $S_{2}^{\text {ed }}$ is unused due to its high concentration and low usability; so it will not be stored but directly discharged in the previous batch. That is why $S_{2}^{\text {ed }}$ does not show up in Fig. 14(b). Since no relatively clean source is remained (in this case, $S_{1}^{\text {ed }}$ and $S_{5}^{\text {ed }}$ ), there is no room for the alteration of inlet concentrations to reduce the size of process unit. 
Table 2

Summary for the network design

\begin{tabular}{|c|c|c|c|c|}
\hline & Freshwater required (ton) & Number of tanks & Capacity of storage (ton) & Water recovery (\%) \\
\hline Base case & 67 & 0 & - & 0.00 \\
\hline Single batch & $\begin{array}{l}44.5 \\
44.5 \\
39.5\end{array}$ & $\begin{array}{l}2 \\
1 \\
-\end{array}$ & $\begin{array}{l}7.5,15 \\
15 \\
-\end{array}$ & $\begin{array}{l}33.58 \\
33.58 \\
41.14\end{array}$ \\
\hline Cyclic batch & $\begin{array}{l}25.75 \\
25.75 \\
25.75\end{array}$ & $\begin{array}{l}3 \\
2 \\
1\end{array}$ & $\begin{array}{l}20,4,2.5 \\
22.5,4.51 \\
31.33\end{array}$ & $\begin{array}{l}61.57 \\
61.57 \\
61.57\end{array}$ \\
\hline
\end{tabular}

Fig. 14(c) shows the scenario of the $4-8.5 \mathrm{~h}$ time interval in the successive batch. $S_{1}$ (20 ton, $0.2 \mathrm{~kg}$ salt $/ \mathrm{kg}$ water) appears in $4-5 \mathrm{~h}$, and $S_{2}$ (16 ton, $0.5 \mathrm{~kg}$ salt $/ \mathrm{kg}$ water) appears in $4.5-5 \mathrm{~h}$. In the 5-6.5 time interval, similar to the situation that has been discussed in single batch, operations 3 is totally fulfilled by water recycle. $S_{4}(13.75$ ton, $0.4 \mathrm{~kg}$ salt $/ \mathrm{kg}$ water) appears in $6.5-7 \mathrm{~h}$. In the 7-8.5 time interval, operations 5 is also fulfilled by water recycle with 2.5 ton of additional freshwater, as denoted by $D_{F W 2}$. Apparently, the quantities of $S_{1}$ and $S_{5}$ are equal to that of $S_{1}^{\text {ed }}$ and $S_{5}^{\text {ed }}$, whereas the quantities of $S_{2}$ and $S_{4}$ are larger than $S_{2}^{\text {ed }}$ and $S_{4}^{\text {ed. }}$. Although it shows the increase of available sources, the excess of $\mathrm{S}_{2}$ and $\mathrm{S}_{4}$ causes no improvement in water recovery. In that case, there is no need to continue the analysis for the next batch since the terminal condition is found. On the other hand, to maintain cyclic operating, the initial and final states in terms of storage in each batch period should be the same. For that reason, $S_{1}$ and $S_{5}$ will be entirely stored for the next batch. As the fact that only 4 ton of $S_{4}^{\text {ed }}$ less than the available ( 9 ton) has been reused, 4 ton of $S_{4}^{\text {ed }}$ and 4 ton of $S_{4}$ kept for the next batch is enough. Hence the surplus $S_{4}^{\text {ed }}$ and $\mathrm{S}_{4}$ will be discharged as wastewater. Moreover, the unused $\mathrm{S}_{2}$ will be directly discharged. Fig. 14(d) shows the reusable water profile with decided storage policy. Note that the source kept from previous batch and generated in present batch have been combined due to the same concentration. $S_{1}^{\text {ed }}$ ( 20 ton) is first consumed by $D_{2}$ ( 12 ton) in $0-0.5 \mathrm{~h}$ and then exhausted by $\mathrm{D}_{4}$ in $2-2.5 \mathrm{~h}$, in a while, 20 ton of $\mathrm{S}_{1}$ generated in $4-5 \mathrm{~h}$ is totally stored. The 4 ton of $S_{4}^{\text {ed }}$ is exhausted by $D_{2}$ in $0-0.5 \mathrm{~h}$, and part of $S_{4}$ ( 4 ton) generated in $6.5-7 \mathrm{~h}$ is stored. $\mathrm{S}_{5}^{\text {ed }}(2.5$ ton $)$ is exhausted by $\mathrm{D}_{4}$ in $2-2.5 \mathrm{~h}$, and 2.5 ton of generation in $7-8.5 \mathrm{~h}$ is totally stored. Consequently, the overall freshwater expenditure is summed of $Q_{1}+3.25+2.5=25.75$ ton per batch, which exhibits a larger amount of water saving than the single batch case.

Considering the different concentration of reusable sources, three storage tanks are firstly placed to store them individually. Fig. 15 shows the resultant network design of cyclic batch with three storage tanks. Tank 1 is used to store $S_{5}$ with the required capacity of 2.5 ton, and tank 2 is used to store $S_{1}$ with the required capacity of 20 ton. Furthermore, tank 3 is used to handle $S_{4}$ and the required capacity is 4 ton. Since the more number of sources to be reused and storage tanks to be placed, the network structure looks quite complex in comparison with the design of single batch.

\subsubsection{Improve the design from the angle of network complexity}

When the freshwater expenditure is determined, we turn to improve the design in terms of network configuration. In practice, the network complexity can be reduced by cutting down the number of storage tanks. On one hand, the simpler network structure will actually facilitate the manipulation and maintenance, on the other hand the less number of storage tanks conceptually reflects the lower capital cost. To decrease the number of storage tanks, that is to say, more than one reusable source will be stored in the same storage tank that involves the mixing of different concentration levels.
Normally, we would like to select the sources with near concentrations. In this case, $S_{1}(0.2 \mathrm{~kg}$ salt $/ \mathrm{kg}$ water $)$ will be collected together with $S_{5}(0.12 \mathrm{~kg}$ salt $/ \mathrm{kg}$ water $)$ as the first step.

In Fig. 16(a), $S_{5}$ is stored with $S_{1}$ after the end of first sequence, the total amount is $20+2.5=22.5$ ton, and the concentration of stock is gradually decreased from 0.2 to $0.191 \mathrm{~kg}$ salt $/ \mathrm{kg}$ water due to the mixing in $7-8.5 \mathrm{~h} . \mathrm{S}_{4}$ is stored solely and the total amount is 9 ton. However, $S_{2}$ is not stored but discharged since it will not be used as discussed previously. Fig. 16(b) shows the scenario of 0-4 h in the successive batch. $D_{1}$ is satisfied by 20 ton of freshwater for its strict limitation in inlet concentration. $\mathrm{D}_{2}$ is satisfied by 11.49 ton of $\left(\mathrm{S}_{1}+\mathrm{S}_{5}\right)^{\text {ed }}$ and 4.51 ton of $\mathrm{S}_{4}^{\text {ed }}$ which give the concentration of $0.25 \mathrm{~kg}$ salt $/ \mathrm{kg}$ water. Next, $\mathrm{D}_{4}$ is satisfied by 11.01 ton of $\left(\mathrm{S}_{1}+\mathrm{S}_{5}\right)^{\text {ed }}$ and 3.25 ton of additional freshwater $\left(D_{F W 1}\right)$ that give the concentration of $0.147 \mathrm{~kg}$ salt $/ \mathrm{kg}$ water. Fig. 16 (c) shows the scenario of $4-8.5 \mathrm{~h}$ in the successive batch. Similar to the previous case, operations 3 and 5 are fulfilled by water recycle with 2.5 ton of additional freshwater $\left(D_{F W 2}\right)$. To maintain cyclic operation, the whole amounts of generated $S_{1}(4-5 h)$ and $S_{5}(7-8.5 h)$ will be stored together. Note that only 4.51 ton of $\mathrm{S}_{4}$ has been reused, which is less than the available $\mathrm{S}_{4}^{\text {ed }}$ ( 9 ton) and $\mathrm{S}_{4}$ generated in 6.5-7 h (14.26 ton). Hence we can shift the reusable water profile of $\left(S_{4}^{e d}+S_{4}\right)$ downward to obtained the fitted size of storage tank, as shown in Fig. 16(d). The overall freshwater consumption is 25.75 ton per batch as before. Fig. 17 shows the resultant network design of cyclic batch with two tanks. Tank 1 is used to collect the mixture of $S_{1}$ and $S_{5}$ with the required capacity of 22.5 ton, and tank 2 is dedicated for $S_{4}$ and the required capacity is 4.51 ton. Obviously, the total amount of storage is slightly increased from 26.5 to 27.01 ton since the raising inlet concentration of operation 4 leads to a larger amount of water requirement.

Afterward, the number of storage tanks can be further reduced. In Fig. 18(a), reusable sources $S_{1}, S_{4}$ and $S_{5}$ are stored together after the end of first sequence. To prevent the probable increase of freshwater requirement, the concentration of stock should not eventually excess the maximum allowable values of operations 2 and 4 . This is because they are the major consumers of those sources from the previous batch, which can be seen in the former analyses. Therefore, the concentration of mixture is set to $0.25 \mathrm{~kg}$ salt $/ \mathrm{kg}$ water and the total storage amount is 31.33 ton, which consists of 20 ton of $S_{1}, 8.83$ ton of $\mathrm{S}_{4}$ and 2.5 ton of $\mathrm{S}_{5}$. The concentration of stock is increased from 0.2 to $0.261 \mathrm{~kg}$ salt $/ \mathrm{kg}$ water in $6.5-7 \mathrm{~h}$, and then gradually decreased to $0.25 \mathrm{~kg}$ salt $/ \mathrm{kg}$ water in $7-8.5 \mathrm{~h}$ for the mixing. Figs. 18 (b) and (c) show the entire operating condition in the successive batch. $\mathrm{D}_{1}$ is satisfied by 20 ton of freshwater, and $D_{2}$ is satisfied by 16 ton of $\left(\mathrm{S}_{1}+\mathrm{S}_{4}+\mathrm{S}_{5}\right)^{\text {ed }}$. $\mathrm{D}_{4}$ is satisfied by 15.33 ton of $\left(\mathrm{S}_{1}+\mathrm{S}_{4}+\mathrm{S}_{5}\right)^{\text {ed }}$ and 3.25 ton of additional freshwater $\left(D_{F W 1}\right)$, which give the concentration of $0.206 \mathrm{~kg}$ salt $/ \mathrm{kg}$ water. As usual, operations 3 and 5 are fulfilled by water recycle with 2.5 ton of additional freshwater $\left(D_{F W 2}\right)$. In addition, 20 ton of $S_{1}, 8.83$ ton of $S_{4}$ and 2.5 ton of $S_{5}$ have been stored to maintain cyclic operation. Consequently, the overall freshwater consumption is 25.75 ton per batch, and the total storage is increased from 27.01 to 31.33 ton. Fig. 19 shows the resultant network design of cyclic batch with only one storage tank. 


\subsection{Summary}

Results, including the freshwater expenditure, number of storage tanks and their respective capacities are summarized in Table 2. Through the water integration, the freshwater consumption of single batch is lowered from 67 to 39.5 ton, which corresponds to a $41.14 \%$ reduction in comparison with the base case. Moreover, the results of cyclic operation shows a still larger amount of water recovery which corresponds to a $61.57 \%$ reduction in freshwater. After the determination of freshwater expenditure, the network configuration becomes another issue to be considered. Then the number of storage tanks is reduced from three to one by the combination of reusable sources with similar concentrations and use that not only simplifies the network complexity, but also reflects a less cost in equipment. Fortunately, there is no freshwater penalty except the increase in total storage amount. However, such result is quite specific to this case study that may not be general. Practically, the freshwater requirement is often increasing when reducing the utilization of storage facilities in batch processes, as a trade-off between utility and capital cost. Up to now, the analyses aim to ideally point out the optimal condition before considering the practical feasibility, and then some operational problems will be discussed in the following section.

\section{Discussion}

\subsection{Check on the optimality}

Since the presented methodology is focused on the part of network design, we need to make sure the optimality of design results by the targeting step of pinch analysis.

For the single batch case, firstly we separate the time horizon into several time intervals according to the starting and finishing times of every operation, and then treat each time interval as a continuous sub-process. After that, the flowrate targeting is done independently in each time interval by any one established targeting method for continuous water system; moreover, the shift of reusable water from the earlier time interval to the later one through the storage facilities is also considered. Such technique is quite similar to the time-dependent heat cascade analysis (Kemp and Deakin, 1989), which gives the freshwater target as 39.5 ton.

For the cyclic batch case, Foo et al. (2005) showed clearly that the utility target for a repeated batch process is exactly the same as in the case of a continuous process, which provides a better means to deal with the problem. Therefore, the flowrate target for cyclic batch can be predicted by the overall utility targeting, where time is entirely ignored as a constraint (analogous to the time average model, TAM, in batch heat integration). Consequently, the freshwater target is determined as 25.75 ton per batch by the time-dependent water cascade analysis (TDWCA, Foo et al., 2005).

Obviously, our design results in Figs. 13, 15, 17 and 19 agree with the freshwater targets from pinch analysis, which means that the maximum water recovery is achieved through the practice of the necessary condition of optimality (Savelski and Bagajewicz, 2000) and the nearest neighbors algorithm (Prakash and Shenoy, 2005) in an ideal situation, i.e. possible for water recycling and no other operational restraints. Detailed data of utility targeting are given in Table 3 and 4 for single and cyclic batch cases.

\subsection{Additional restraint on water reuse}

In some cases, the operational restraints are critical to be considered due to the request of quality control, or the prevention of probable pollution. For example, water reuse between assigned process
Table 3

Freshwater targeting for single batch

\begin{tabular}{lllll}
\hline $\begin{array}{l}\text { Time } \\
\text { period }\end{array}$ & $\begin{array}{l}\text { Start } \\
(\mathrm{h})\end{array}$ & $\begin{array}{l}\text { Finish } \\
(\mathrm{h})\end{array}$ & $\begin{array}{l}\text { Freshwater } \\
\text { required (ton) }\end{array}$ & $\begin{array}{l}\text { Wastewater } \\
\text { generated (ton) }\end{array}$ \\
\hline 1 & 0.0 & 0.5 & 18.0 & 0.0 \\
2 & 0.5 & 1.0 & 10.0 & 0.0 \\
3 & 2.0 & 2.5 & 9.0 & 0.0 \\
4 & 4.0 & 4.5 & 0.0 & 10.0 \\
5 & 4.5 & 5.0 & 0.0 & 18.0 \\
6 & 5.0 & 6.5 & 0.0 & 0.0 \\
7 & 6.5 & 7.0 & 0.0 & 9.0 \\
8 & 7.0 & 8.5 & 2.5 & 2.5 \\
\multicolumn{2}{l}{ Total amount } & & 39.5 & 39.5 \\
\hline
\end{tabular}

Table 4

Freshwater targeting for cyclic batch

\begin{tabular}{llcccc}
\hline $\begin{array}{l}\text { Concentration } \\
(\mathrm{kg} / \mathrm{kg})\end{array}$ & $\begin{array}{l}\Delta C \\
(\mathrm{~kg} / \mathrm{kg})\end{array}$ & $\begin{array}{l}\Delta Q \\
\text { (ton) }\end{array}$ & $\begin{array}{l}\text { cum. } Q \\
\text { (ton) }\end{array}$ & $\begin{array}{l}\Delta m \\
\text { (ton) }\end{array}$ & $\begin{array}{l}\text { cum. } \Delta m \\
\text { (ton) }\end{array}$ \\
\hline 0 & & -20 & 25.75 & & 0 \\
0.1 & 0.1 & -15 & 5.75 & 0.575 & 0.575 \\
0.12 & 0.02 & 15 & -9.75 & -0.185 & 0.39 \\
0.2 & 0.08 & 20 & 5.75 & 0.46 & 0.85 \\
0.25 & 0.05 & -40 & 25.75 & 1.2875 & 2.1375 \\
0.4 & 0.15 & 24 & -14.25 & -2.1375 & 0 \\
0.5 & 0.1 & 16 & 9.75 & 0.975 & 0.975 \\
1 & 0.5 & & 25.75 & 12.875 & 13.85 \\
\hline
\end{tabular}

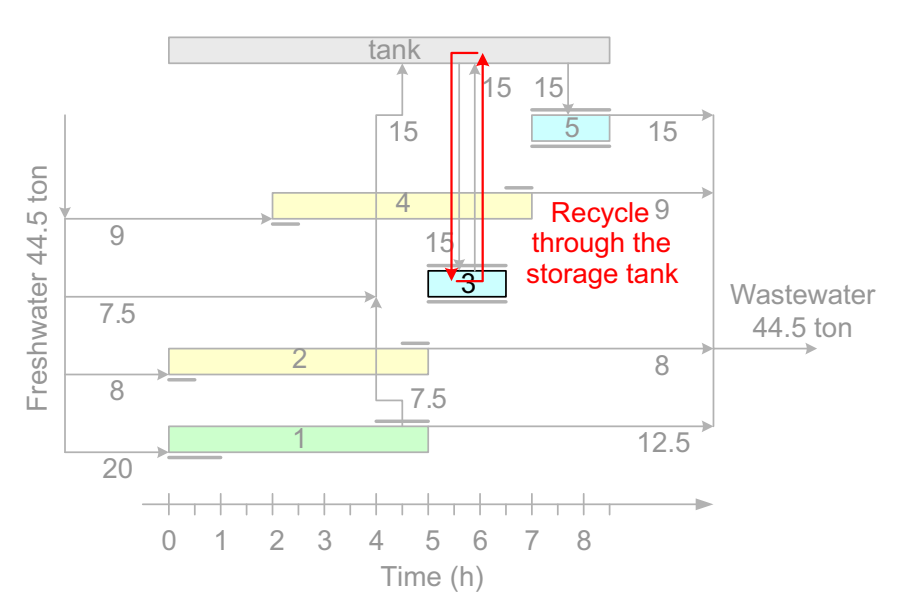

Fig. 20. Water recycle in operation 3 through the storage tank.

units will be forbidden even though the apparent concentrations are in the tolerable range. This is because the buildup of some chemicals may cause severe problem to the operation, but those chemicals have not been considered as the key component in the problem specification. To avoid the undesirable match between specific demand and source, the route of concerned streams should be carefully checked.

Now we suppose that the water recycle in operation 3 is forbidden, that is, demand $\mathrm{D}_{3}$ cannot be supplied by source $\mathrm{S}_{3}$. In this case, the design for single batch in Fig. 13 becomes infeasible and then we have no alternative but to seek what is less attractive than the optimum. However, as shown in Fig. 20, the design for single batch with one storage tank is still infeasible, because the outlet water of 
a

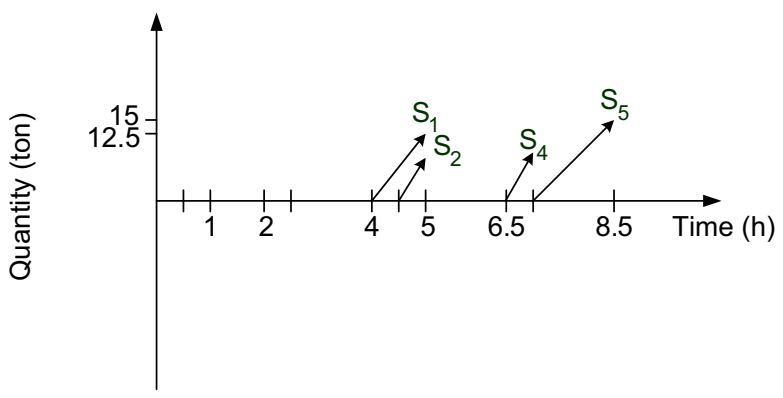

C

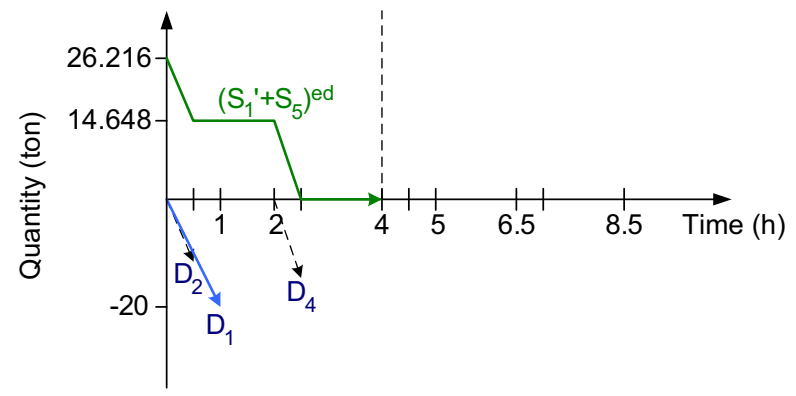

b

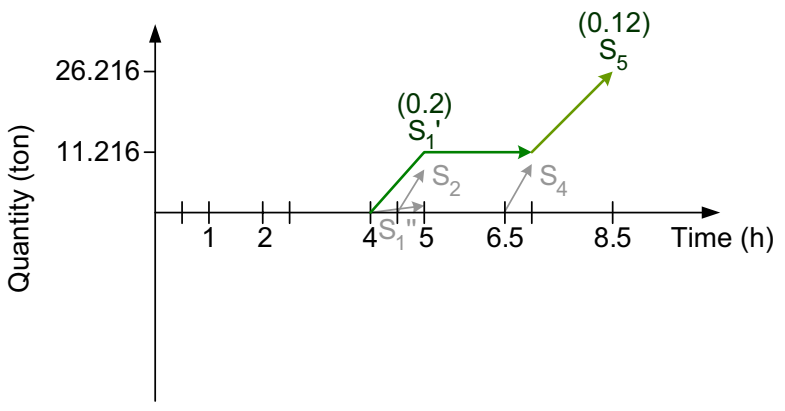

d

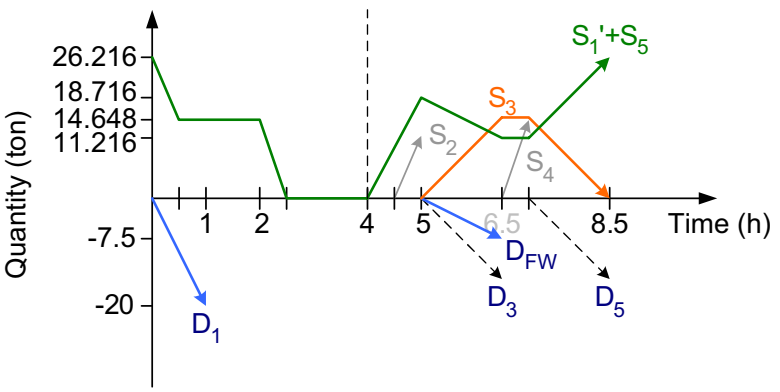

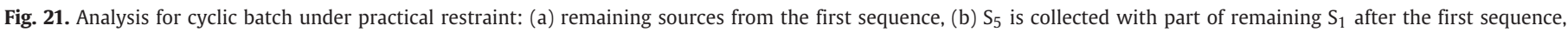
(c) the scenario of $0-4 \mathrm{~h}$ and (d) $4-8.5 \mathrm{~h}$ in the successive batch.
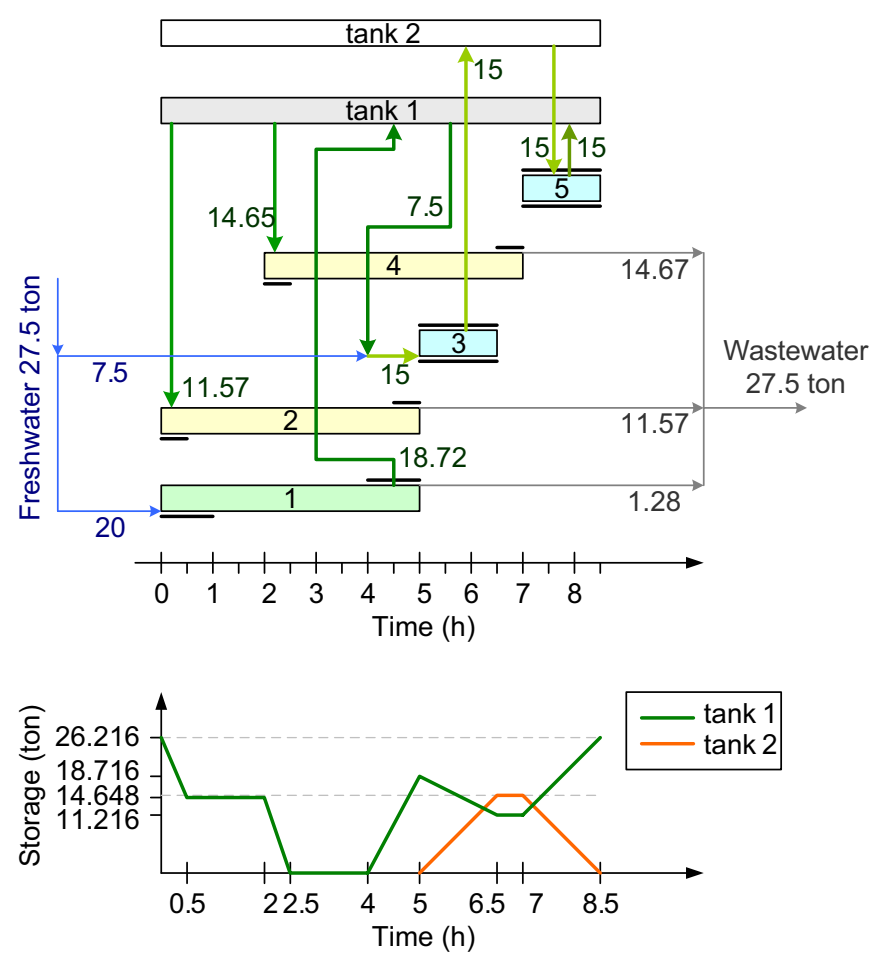

Fig. 22. Resultant network of cyclic batch under practical restraint: two storage tanks.

operation 3 is recycled through the storage tank. Therefore, for single batch, Fig. 9 becomes the only practicable solution with the raised freshwater consumption (from 39.5 to 44.5 ) and cost in storage facilities (two storage tanks have to be placed). Similarly, the design for cyclic batch in Figs. 15, 17 and 19 are also impracticable since all of these analyses are based on the single batch design with water recycle in Figs. 12 and 13.

Figs. 21(a)-(d) show the analysis for cyclic batch under the restraint that water recycle in operation 3 is forbidden. The analysis is based on the result of single batch in Fig. 9. Fig. 21(a) shows the remaining sources from the first sequence including $S_{1}$ (12.5 ton), $S_{2}$ ( 8 ton), $S_{4}$ (9ton) and $S_{5}$ (15ton). The concentrations of those sources are $0.2,0.5,0.4$ and $0.12 \mathrm{~kg}$ salt $/ \mathrm{kg}$ water, respectively. Since operation 5 is fulfilled by the outlet water of operation $3\left(S_{3}\right)$ in the first sequence, to supply operation 3 in the successive batch by the output of operation $5\left(\mathrm{~S}_{5}\right)$ is definitely not allowed, or water will be recycled to operation 3 via process unit and storage tank. Therefore, in the successive batch, $D_{3}$ has to be supplied by $S_{1}$ with freshwater and then $D_{5}$ can be satisfied by $S_{3}$, as the pattern in Figs. 7(c) and (e). As the aforementioned, $D_{1}$ can be only satisfied by freshwater; so $D_{2}$ and $\mathrm{D}_{4}$ do the major consumers of those remaining sources from previous batch. For this case, both $\mathrm{S}_{2}$ and $\mathrm{S}_{4}$ are excluded, because it can be found that only $S_{1}$ and $S_{5}$ are sufficient for $D_{2}$ and $D_{4}$. If we store the whole amounts of $S_{1}$ and $S_{5}$, there will be $12.5+15=27.5$ ton of mixture with the concentration of $0.156 \mathrm{~kg}$ salt $/ \mathrm{kg}$ water that can be used to satisfy $D_{2}$ and $D_{4}$ with a surplus of 1.08 ton. Hence $S_{1}$ and $\mathrm{S}_{5}$ are just enough for those demands, and their relatively low concentrations also lead to a smaller size of equipment. Furthermore, it is workable to collect $S_{1}$ and $S_{5}$ together to reduce the number of storage tanks as well as the network complexity.

Fig. 21(b) shows that 11.22 ton of $S_{1}$ (denoted as $S_{1}^{\prime}$ ) and 15 ton of $\mathrm{S}_{5}$ to be stored and the concentration of stock is eventually $0.154 \mathrm{~kg}$ salt $/ \mathrm{kg}$ water after the end of first sequence. The total amount of storage is 26.22 ton that is exactly enough for $D_{2}$ and $D_{4}$, and the surplus of $S_{1}$ (denoted as $S_{1}^{\prime \prime}$ ) will be discharged with the other unused sources $S_{2}$ and $S_{4}$. As shown in Fig. 21(c), $D_{2}$ is satisfied by 11.57 ton of $\left(\mathrm{S}_{1}^{\prime}+\mathrm{S}_{5}\right)^{\text {ed }}$, and $\mathrm{D}_{4}$ is satisfied by 14.65 ton of $\left(\mathrm{S}_{1}^{\prime}+\right.$ $\left.S_{5}\right)^{\text {ed }}$. After that, in Fig. 21(d), $D_{3}$ is satisfied by 7.5 ton of $S_{1}$ with 7.5 ton of freshwater, and $D_{5}$ is fully satisfied by $S_{3}$. In addition, $11.22+7.5=18.72$ ton of $S_{1}$ has been stored in $4-5 \mathrm{~h}$ to maintain cyclic operating, where 7.5 ton is consumed later and 11.22 ton is 
Table 5

Summary for the network design with imposed restraint

\begin{tabular}{|c|c|c|c|c|}
\hline & Freshwater required (ton) & Number of tanks & Capacity of storage (ton) & Water recovery (\%) \\
\hline Base case & 67 & 0 & - & 0.00 \\
\hline Single batch & 44.5 & 2 & $7.5,15$ & 33.58 \\
\hline \multirow[t]{2}{*}{ Cyclic batch } & 27.5 & 3 & $18.12,15,15$ & 58.95 \\
\hline & 27.5 & 2 & $26.22,15$ & 58.95 \\
\hline
\end{tabular}
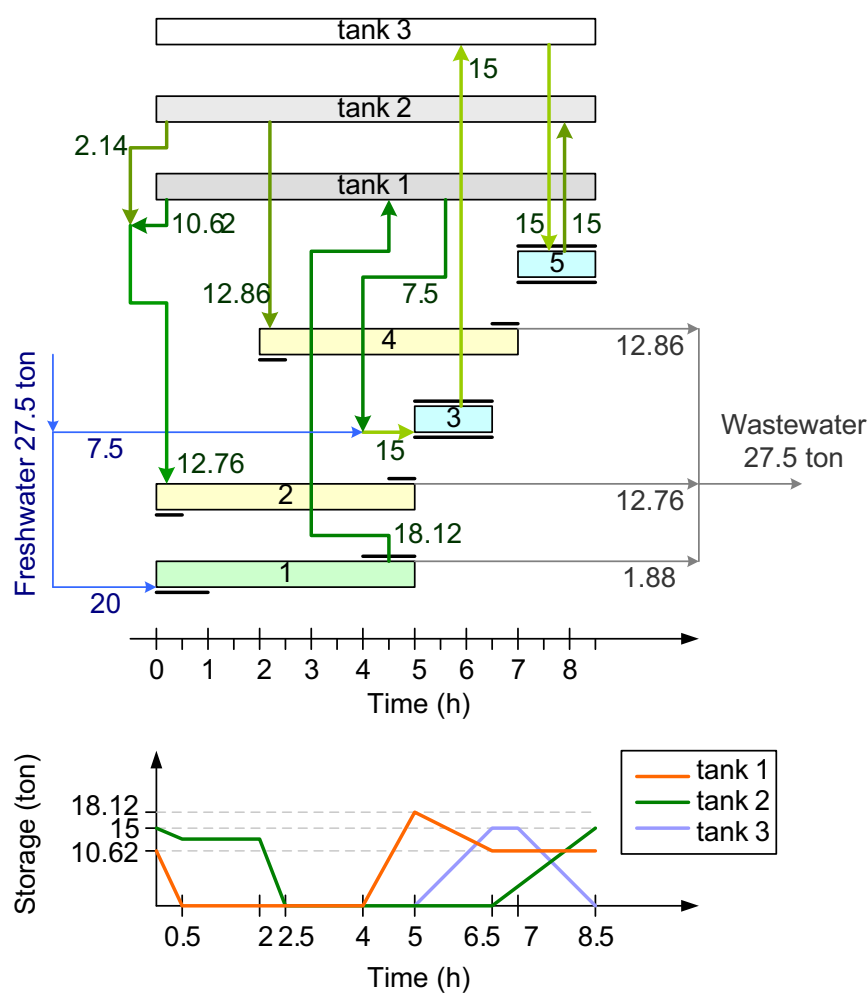

Fig. 23. Resultant network of cyclic batch under practical restraint: three storage tanks.

kept for the next batch. Consequently, the overall freshwater consumption is 27.5 ton per batch, which is higher than the original optimum ( 25.75 ton per batch) due to the forbiddance of water recycle in operation 3.

Fig. 22 shows the resultant network design of cyclic batch under practical restraint. Tank 1 is used to collect the mixture of $S_{1}$ and $\mathrm{S}_{5}$ with the required capacity of 26.22 ton, and tank 2 is dedicated for $S_{3}$ and the required capacity is 15 ton. The design results with imposed restraint, including both single batch and cyclic batch are summarized in Table 5 . By contrast, the more equipment may be equipped but the less amount of water recovery can be obtained, which means that the effect of process integration is diminished by the additional limitation. Moreover, because it is not allowed to supply operation 3 by the output of operation 5 , the freshwater consumption will not decrease even if one more storage tank is placed (as shown in Fig. 23).

\section{Conclusions}

This paper presents a clear and straight forward technique for the design of water-using network in batch processes. Firstly, the proposed graphical approach is performed to determine the freshwater expenditure and visualize the network structure, as well as the storage policy. Secondly, practicable ways are sought to reduce the number of storage tanks and simplify the network complexity. Finally, the design results are compared to the utility targets from pinch analysis to check the optimality, and it can be seen that the maximum water recovery is accomplished by the proposed principles for stream allocation. Although the analyses in this work are actually focused on the mass transfer based operations, the proposed method is not limited to such type of problems. As the representation about separating the operations into water demands and water sources introduced by Dhole et al. (1996) is adopted in problem formulation, the method is capable to deal with the non-mass transfer based or fixed flowrate operation expectably. Unfortunately, the presented methodology in this work is restricted to the system with single key contaminant, like most graphical techniques to date. Through water integration, the freshwater consumption is considerably lowered in contrast to the base case, more than $40 \%$ and $60 \%$ of water savings in single batch and cyclic batch, respectively. However, in some cases the maximum water recovery becomes inaccessible because of the operational restraints on design. When water recycling in operation 3 is forbidden, the accessible amount of water recovery for single batch and cyclic batch are decreased to $33.58 \%$ and $58.95 \%$, respectively. As a result, the constraint on water recycle not only troubles the designer, but also confines the effect of water integration.

\section{Notation}

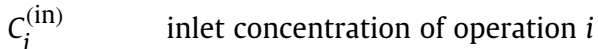

$C_{i, \max }^{(\text {in) }}$

$C_{i}^{\text {(out) }}$

$C_{i, \text { max }}$

$C_{i}^{\mathrm{D}} \quad$ concentration of the corresponding demand of operation $i$

$C_{j}^{\mathrm{D}} \quad$ specified concentration of the $j$ th demand for fixed quantity

operations

$C_{i}^{S} \quad$ concentration of the corresponding source of operation $i$

$C_{k}^{S} \quad$ specified concentration of the $k$ th source for fixed quantity operations

$\mathrm{D}_{F W} \quad$ additional demand of freshwater for dilution

$\mathrm{D}_{i} \quad$ corresponding demand of operation $i$

$\mathrm{D}_{j} \quad$ the $j$ th demand for fixed quantity operations

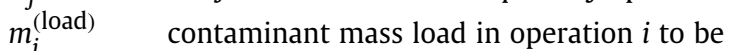
removed

$Q_{i} \quad$ water requirement of operation $i$

$Q_{i}^{\mathrm{D}} \quad$ quantity of the corresponding demand of operation $i$

$Q_{j}^{\mathrm{D}} \quad$ specified quantity of the $j$ th demand for fixed quantity operations

$Q_{i}^{S} \quad$ quantity of the corresponding source of operation $i$

$Q_{k}^{S} \quad$ specified quantity of the $k$ th source for fixed quantity operations

$S_{i} \quad$ corresponding source of operation $i$

$S_{k} \quad$ the $k$ th source for fixed quantity operations 


\section{Subscripts}

$i$

$j$

$k$

set of fixed load operations in batch processes set of demands for fixed quantity operations in batch processes

set of sources for fixed quantity operations in batch processes

\section{Superscripts}

ed

denotes the source is the remainder from previous batch

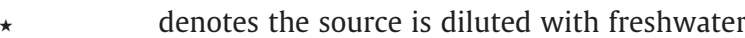

\section{References}

Castro, P., Matos, H., Fernandes, M.C., Pedro Nunes, C., 1999. Improvements for massexchange networks design. Chemical Engineering Science 54 (11), 1649-1665.

Chan, J.H., Foo, C.Y., Kumaresan, S., Aziz, A., Abu-Hassan, M.A., 2008. An integrated approach for water minimization in a PVC manufacturing process. Clean Technologies and Environmental Policy 10 (1), 67-79.

Dhole, V.R., Ramchandi, N., Tainsh, R.A., Wasilewski, M., 1996. Make your process water pay itself. Chemical Engineering 103 (1), 100-103.

El-Halwagi, M.M., 1997. Pollution Prevention Through Process Integration: Systematic Design Tools. Academic Press, San Diego.

El-Halwagi, M.M., Gabriel, F., Harell, D., 2003. Rigorous graphical targeting for resource conservation via material recycle/reuse networks. Industrial and Engineering Chemistry Research 42 (19), 4319-4328.

Feng, X., Seider, W.D., 2001. New structure and design methodology for water networks. Industrial and Engineering Chemistry Research 40 (26), 6140-6146.

Foo, C.Y., Manan, Z.A., Tan, Y.L., 2005. Synthesis of maximum water recovery network for batch process systems. Journal of Cleaner Production 13 (15), 1381-1394.
Gomes, J.F.S., Queiroz, E.M., Pessoa, F.L.P., 2007. Design procedure for water/wastewater minimization: single contaminant. Journal of Cleaner Production 15 (5), 474-485.

Hallale, N., 2002. A new graphical targeting method for water minimization. Advances in Environmental Research 6 (3), 377-390.

Kemp, I.C., Deakin, A.W., 1989. The cascade analysis for energy and process integration of batch processes, part 1 . Transactions of the Institute of Chemical Engineers 67 (Part A), 495-509.

Kuo, W.-C.J., Smith, R., 1998. Designing for the interactions between water-use and effluent treatment. Transaction of the Institute of Chemical Engineers 76 (Part A), 287-301.

Liu, Y.J., Yuan, X.G., Luo, Y.Q., 2007a. Synthesis of water utilization system using concentration interval analysis method (I) non-mass-transfer-based operation. Chinese Journal of Chemical Engineering 15 (3), 361-368.

Liu, Y.J., Yuan, X.G., Luo, Y.Q., 2007b. Synthesis of water utilization system using concentration interval analysis method (II) discontinuous process. Chinese Journal of Chemical Engineering 15 (3), 369-375.

Majozi, T., Brouckaert, C.J., Buckley, C.A., 2006. A graphical technique for wastewate minimization in batch processes. Journal of Environmental Management 78 (4) 317-329.

Manan, Z.A., Foo, C.Y., Tan, Y.L., 2004. Targeting the minimum water flow rate using water cascade analysis technique. A.I.Ch.E. Journal 50 (12), 3169-3183.

Prakash, R. Shenoy, U.V., 2005. Targeting and design of water networks for fixed flowrate and fixed contaminant load operations. Chemical Engineering Science 60 (1), 255-268.

Savelski, M.J., Bagajewicz, M.J., 2000. On the optimality conditions of water utilization systems in process plants with single contaminants. Chemical Engineering Science 55 (1), 5035-5048

Wang, Y.P., Smith, R., 1994. Wastewater minimization. Chemical Engineering Science 49 (7), 981-1006.

Wang, Y.P., Smith, R., 1995a. Wastewater minimization with flowrate constraints. Transaction of the Institute of Chemical Engineers 73 (Part A), 889-904.

Wang, Y.P., Smith, R., 1995b. Time pinch analysis. Transaction of the Institute of Chemical Engineers 73 (Part A), 905-914. 